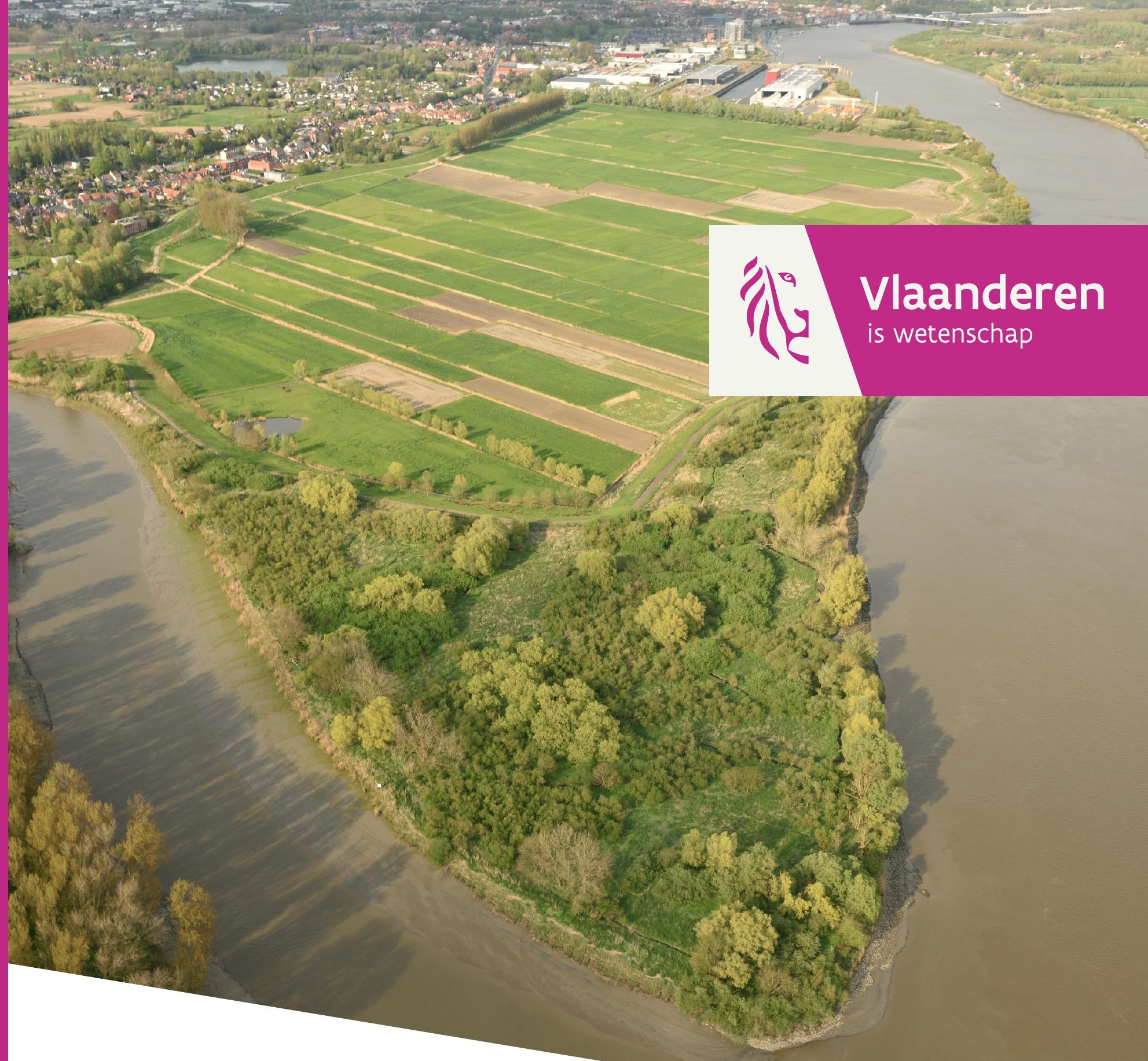

\title{
Biologische Waarderingskaart en Natura 2000 Habitatkaart, uitgave 2020
}

Steven De Saeger, Robin Guelinckx, Patrik Oosterlynck, Adinda De Bruyn, Klaas Debusschere, Pieter Dhaluin, Rémar Erens, Pieter Hendrickx, Dirk Hennebel, Indra Jacobs, Myriam Kumpen, Jorgen Opdebeeck, Toon Spanhove, Ward Tamsyn, Frank Van Oost, Guy Van Dam, Martine Van Hove, Carine Wils \& Desiré Paelinckx 


\section{Auteurs:}

Steven De Saeger, Robin Guelinckx, Patrik Oosterlynck, Adinda De Bruyn, Klaas Debusschere, Pieter Dhaluin, Rémar Erens, Pieter Hendrickx, Dirk Hennebel, Indra Jacobs, Myriam Kumpen, Jorgen Opdebeeck, Toon Spanhove, Ward Tamsyn, Frank Van Oost, Guy Van Dam, Martine Van Hove, Carine Wils \& Desiré Paelinckx

Instituut voor Natuur- en Bosonderzoek

\section{Reviewers:}

Desiré Paelinckx

Het INBO is het onafhankelijk onderzoeksinstituut van de Vlaamse overheid dat via toegepast wetenschappelijk onderzoek, data- en kennisontsluiting het biodiversiteitsbeleid en -beheer onderbouwt en evalueert.

\section{Vestiging:}

Herman Teirlinckgebouw

INBO Brussel

Havenlaan 88 bus 73, 1000 Brussel

www.inbo.be

\section{e-mail:}

bwk@inbo.be

\section{Wijze van citeren:}

De Saeger S., Guelinckx R., Oosterlynck P., De Bruyn A., Debusschere K., Dhaluin P., Erens R., Hendrickx P., Hendrix R., Hennebel D., Jacobs I., Kumpen M., Opdebeeck J., Spanhove T., Tamsyn W., Van Oost F., Van Dam G., Van Hove M., Wils C. \& Paelinckx D. (red.) (2020). Biologische Waarderingskaart en Natura 2000 Habitatkaart, uitgave 2020. Rapporten van het Instituut voor Natuur- en Bosonderzoek 2000 (35). Instituut voor Natuur- en Bosonderzoek, Brussel.

DOI: doi.org/10.21436/inbor.18840851

D/2020/3241/252

Rapporten van het Instituut voor Natuur- en Bosonderzoek 2020 (35)

ISSN: 1782-9054

Verantwoordelijke uitgever:

Maurice Hoffmann

Foto cover:

Polder van Tielrode in Temse (Vildaphoto / Yves Adams) 


\section{Vlaanderen}

\section{is wetenschap}

\section{Biologische Waarderingskaart en Natura 2000 Habitatkaart, uitgave 2020}

Steven De Saeger, Robin Guelinckx, Patrik Oosterlynck, Adinda De Bruyn, Klaas Debusschere, Pieter Dhaluin, Rémar Erens, Pieter Hendrickx, Dirk Hennebel, Indra Jacobs, Myriam Kumpen, Jorgen Opdebeeck, Toon Spanhove, Ward Tamsyn, Frank Van Oost, Guy Van Dam, Martine Van Hove, Carine Wils \& Desiré Paelinckx (red.) 


\section{Dankwoord/Voorwoord}

Deze uitgave van de BWK en habitatkaart is, net zoals de vorige versies (o.a. De Saeger et al. 2018), tot stand gekomen door de inzet van een grote groep INBO-medewerkers en externe experten. Hierbij willen we iedereen bedanken die een kleine of grote bijdrage geleverd heeft aan het tot stand komen van deze kaarten.

De veldkarteerders van het vaste BWK-team worden in onderstaand overzicht alfabetisch opgelijst voor zover er in dit digitaal geografisch bestand beduidende arealen resten van hun karteringen.

Periode 2013 - 2020

Rémar Erens

Robin Guelinckx

Dirk Hennebel

Periode 2016 - 2019

Adinda De Bruyn

Klaas Debusschere

Pieter Dhaluin

Pieter Hendrickx

Periode 2005 - 2012

Yves Adams

Bert Berten

Hans Bosch

Geert De Knijf

Steven De Saeger

Periode vóór 2005

\section{Griet Ameeuw}

Yves Adams

Bert Berten

Hans Bosch

Geert De Knijf

Steven De Saeger

Heidi Demolder

Inge Brichau

Arnout Zwaenepoel

Databank en validatie

Guy Van Dam

Carine Wils

Steven De Saeger

Bert Mintiens
Patrik Oosterlynck

Frank Van Oost

Steven De Saeger

\section{Roy Hendrix}

Toon Spanhove

Myriam Kumpen

Jorgen Opdebeeck

Jan Ruymen

Ward Tamsyn
Filiep T'Jollyn Jan Van Ormelingen Martine Van Hove Veerle Vandenbussche Lieve Vriens
Samantha Delafaille Kristof Scheldeman Leen Durwael

Gabriël Erens

Robin Guelinckx Johan Heirman

Patrick Lust

Patrik Oosterlynck

Kris Rombouts
Jan Van Ormelingen

Regine Vanallemeersch

Martine Van Hove

Veerle Vandenbussche

Maarten Vanderhallen

Lieve Vriens
Filiep T'Jollyn

\section{Supervisie}

Desiré Paelinckx

Meer detail over de persoonlijke bijdragen (uit de periode vóór 2012) van de veldkarteerders kan men terugvinden in de metadata-teksten per kaartblad (zie § Referenties). 


\section{Samenvatting}

De Biologische Waarderingskaart (BWK) is een gebiedsdekkende inventaris van het biologische milieu en van de bodembedekking van het volledige Vlaams Gewest. De kaart is het resultaat van een inventarisatie met behulp van vooraf gedefinieerde karteringseenheden.

Naast de BWK bevat de kaart ook de Natura 2000 habitattypen. In Vlaanderen komen actueel 46 Natura 2000 habitattypen van de Bijlage I van de Habitatrichtlijn voor. Enkel habitattype 8310 (niet voor publiek opengestelde grotten) ontbreekt in deze kaart (De Saeger et al. 2020). Daarnaast zijn er in Vlaanderen ook 16 regionaal belangrijke biotopen gedefinieerd. Dit zijn biotopen die in Vlaanderen een wettelijke bescherming genieten en naar biologische waarden en belang voor de biodiversiteit vergelijkbaar zijn met habitattypen, maar die op Europees niveau niet beschermd zijn.

Dit rapport bevat de metadata en is een toelichting bij het digitale bestand 'Biologische Waarderingskaart en Natura 2000 Habitatkaart, uitgave 2020'. Deze kaart geeft de best beschikbare informatie anno 2020 over de verspreiding van de Natura 2000 habitattypen, de regionaal belangrijke biotopen en de karteringseenheden van de Biologische Waarderingskaart. Dit kan een vereenvoudiging zijn van de werkelijkheid op terrein. Te allen tijde geldt de reële situatie op het terrein voor toepassing t.b.v. het beleidsmatige en wettelijke kader.

Deze uitgave van de BWK en Natura 2000 habitatkaart is enkel als digitaal bestand beschikbaar. Het bestand moet steeds gebruikt worden in combinatie met de afbakening van de gebieden belangrijk voor fauna-elementen (De Knijf et al. 2010).

De kaarten zijn voor iedereen online en interactief raadpleegbaar via het geoportaal van Geopunt Vlaanderen (www.geopunt.be).

Gebruikers die zelf over GIS-software beschikken kunnen de kaarten (incl. lookup-tabellen, legendes en rapporten) downloaden via de Catalogus van Geopunt Vlaanderen of de downloadtoepassing van het Agentschap Informatie Vlaanderen (https://download.agiv.be/), of raadplegen via WMS.

Gelieve bij gebruik van het digitale bestand, hier ook steeds correct naar te refereren (zie colofon). 


\section{English abstract}

The Biological Valuation Map (BVM) is a uniform field-driven survey of the land cover and vegetation in the Flemish Region. The map is drawn at a detailed scale of 1/5 000. Land cover classes and vegetation types are defined by an extensive list of legend units. For fast and easy interpretation the survey is also translated into a biological valuation and depicted by a colour code on the map. More background information on www.inbo.be/bvm and in De Saeger et al. (2017).

The Natura 2000-habitatmap is also a uniform field-driven survey. It is based on the Biological Valuation Map (BVM) and is an important instrument in locating and quantifying the amount of 45 of the 46 Natura 2000 habitats in Flanders. Only habitattype 8310 (caves not open to the public) is missing from this map.

In 2020 a new version of the Biological Valuation Map (BVM) and the Natura 2000-habitatmap was published. These new maps can be consulted online (www.geopunt.be).

In the map application there is a selection menu on the right. For the consultation of both maps you first have to choose the theme 'Milieu en natuur' in the selection list followed by 'natuur'. Next, select the layers 'Biologische waarderingskaart' - versie 2 and 'Kaartlabels Biologische waarderingskaart - karteringseenheden' for the Biological Valuation Map or 'Natura 2000 Habitatkaart' and 'Kaartlabels Natura 2000 Habitat' for the Natura 2000habitatmap. The layers are only visible from the scale of 1: 45000 and beyond. Zooming to a municipality or street is possible using the search option.

Users with access to GIS-software (there is free GIS-software available online) can download both maps (https://download.agiv.be/, search for 'Biologische Waarderingskaart en Natura 2000 Habitatkaart - Toestand $2020^{\prime}$ ), available in both shapefile and GML-format. 


\section{Inhoudstafel}

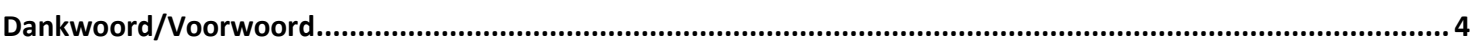

\section{Samenvatting 5}

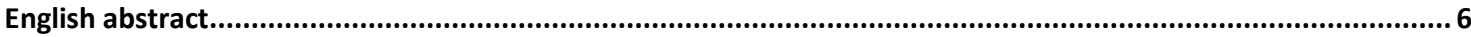

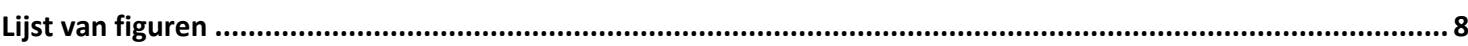

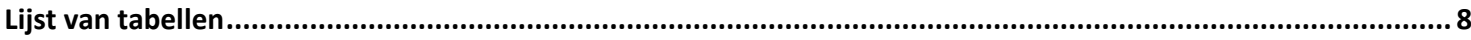

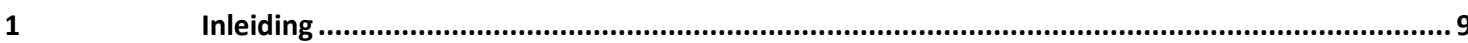

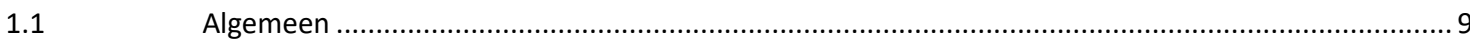

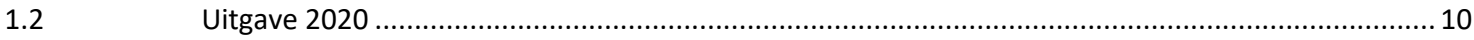

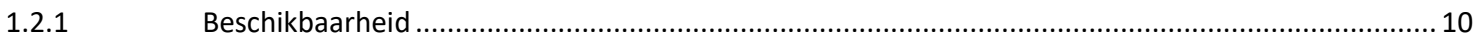

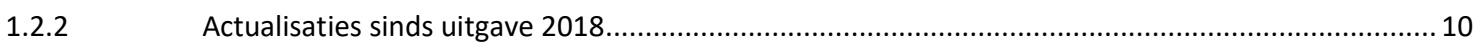

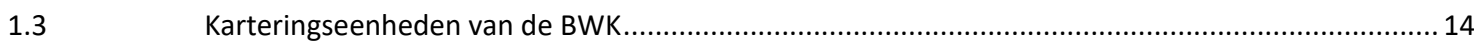

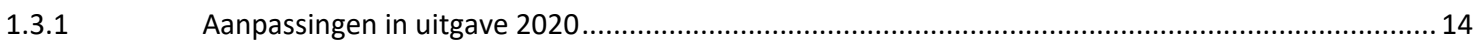

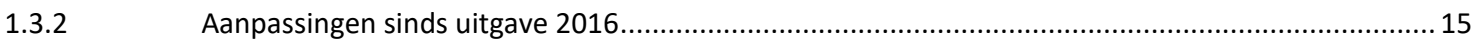

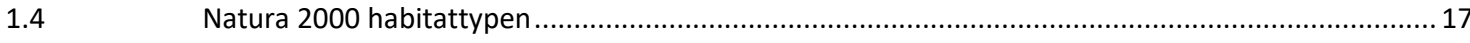

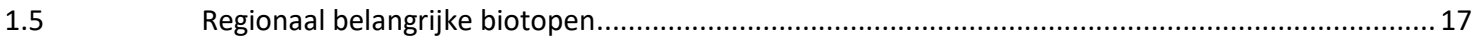

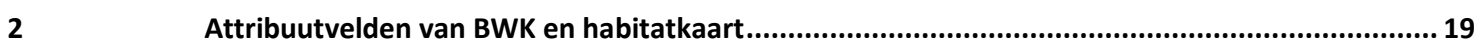

2.1 Attribuutvelden met de informatie van de Biologische Waarderingskaart..................................... 19

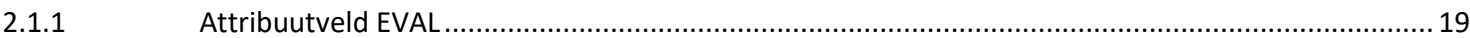

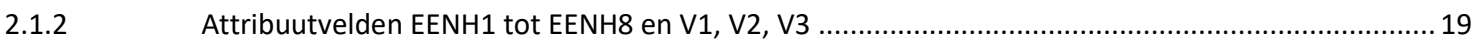

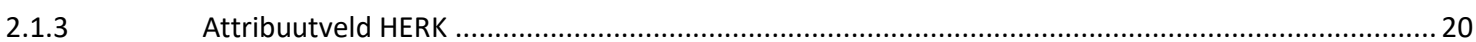

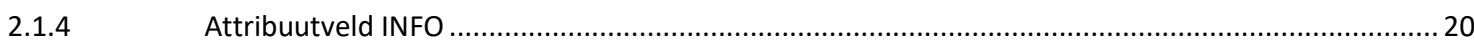

2.2 Attribuutvelden met de informatie over de Natura 2000 habitattypen en de regionaal belangrijke

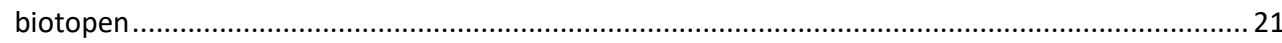

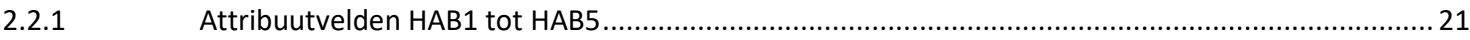

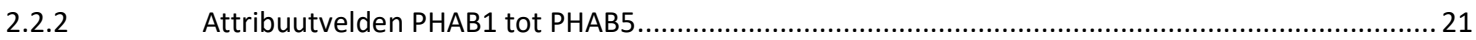

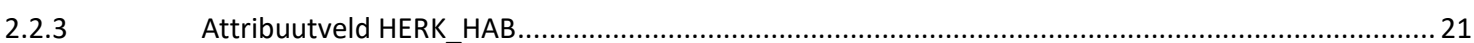

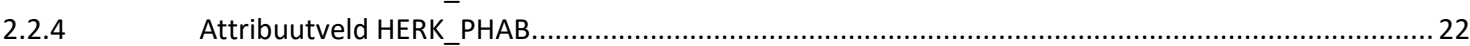

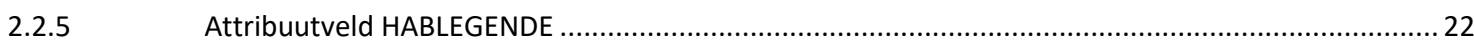

Referenties 23 


\section{Lijst van figuren}

Figuur 1-1 Vergelijking tussen de herkomstperiode van BWK-habitatkaart uitgave 2018 en 2020 voor heel Vlaanderen, exclusief het urbaan gebied (zie § 2.1.3 voor duiding over de legende in de X-as).

Figuur 1-2 Vergelijking tussen de herkomstperiode van BWK-habitatkaart uitgave 2018 en 2020 binnen de habitatrichtlijngebieden (SBZ-H), exclusief het urbaan gebied (zie § 2.1.3 voor duiding over de legende in de $\mathrm{X}$-as).......

Figuur 1-3 Indicatie van de herkomst, ligging en ruimtelijke spreiding van de aanpassingen aan de BWK-habitatkaart 2020 sinds de publicatie van de vorige versie in 2018

\section{Lijst van tabellen}

Tabel 1-1 Overzicht van de 'nieuwe' karteringseenheden (KE) in BWK, uitgave 2020.

Tabel 1-2 Overzicht van de 'nieuwe' karteringseenheden (KE) in BWK, uitgave 2016.

Tabel 1-3 Indicatieve vergelijking tussen BWK-habitatkaart uitgave 2018 en 2020 wat betreft de oppervlakte aan polygonen die als kennislacune zijn aangeduid (code 'ohab' in de Habitat-legende)...............................17

Tabel 1-4 Regionaal belangrijke biotopen in Vlaanderen in de habitatkaart, uitgave 2020 .........................................18

Tabel 2-1 Betekenis van de codes van het attribuutveld EVAL van de BWK …..............................................................19

Tabel 2-2 Voorbeelden van de belangrijkste verschillen in de notatie van de karteringseenheden (KE) in de digitale

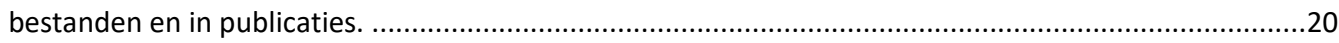

Tabel 2-3 Betekenis van de codes van het attribuutveld HERK van de BWK …..........................................................20

Tabel 2-4 Automatische verdeelsleutel voor complexen van habitattypen bij automatische vertaling uit de BWKkartering. 


\section{Inleiding}

Dit rapport bevat de metadata van en is een toelichting bij het digitale bestand 'Biologische Waarderingskaart en Natura 2000 Habitatkaart, uitgave 2020'. Gelieve bij gebruik van het digitale bestand, hier ook steeds correct naar te refereren (zie colofon).

Deze uitgave 2020 vervangt alle vorige versies van de BWK en van de habitatkaart.

Deze versie van de Biologische Waarderingskaart en de habitatkaart geeft de best beschikbare informatie anno 2020 weer over de verspreiding van de Natura 2000 habitattypen, de regionaal belangrijke biotopen en de karteringseenheden van de Biologische Waarderingskaart. Dit kan een vereenvoudiging zijn van de werkelijkheid op terrein. Te allen tijde geldt de reële situatie op het terrein voor toepassing t.b.v. het beleidsmatig en wettelijk kader.

Dit bestand moet gebruikt worden in combinatie met de afbakening van de gebieden belangrijk voor fauna-elementen: De Knijf et al. 2010.

Noch de auteurs noch het Instituut voor Natuur- en Bosonderzoek kunnen verantwoordelijk gesteld worden voor gebeurlijke fouten en de gevolgen die daaruit kunnen voortvloeien.

De gebruiker wordt verzocht elke onvolkomenheid (of twijfel daarover) mede te delen via bwk@inbo.be.

\subsection{Algemeen}

De Biologische Waarderingskaart (BWK) is een gebiedsdekkende inventaris van het biologische milieu en van de bodembedekking van het volledige Vlaams Gewest. Deze kaart is het resultaat van een zo gestandaardiseerd mogelijke inventarisatie met behulp van vooraf gedefinieerde codes, karteringseenheden genaamd (§ 1.3). Om de kaart makkelijk en snel interpreteerbaar te maken voor het beleid is er een 'biologische' waardering aan gekoppeld. Op de BWK krijgen bepaalde gebieden ook een afzonderlijke aanduiding omwille van de aanwezigheid van bepaalde fauna-elementen. Hiervoor is een afzonderlijk bestand en rapport beschikbaar (De Knijf et al. 2010). Voor meer informatie over de BWK wordt verwezen naar Vriens et al. 2011, Weblink 1 en www.inbo.be/bwk.

Deze uitgave geeft de best beschikbare informatie anno 2020 weer over de verspreiding van de Natura 2000 habitattypen, de regionaal belangrijke biotopen en de karteringseenheden van de Biologische waarderingskaart ( $\$ 0$ \& 1.5).

Deze indicatieve situering is de resultante van:

- $\quad$ gericht veldwerk: sinds 2004 wordt tijdens de BWK-kartering steeds ook het Natura 2000 habitattype of regionaal belangrijk biotoop genoteerd;

- $\quad$ een vertaling van de karteringseenheden van de Biologische Waarderingskaart naar de Natura 2000 habitattypen en regionaal belangrijke biotopen (vnl. karteringen van vóór 2004 en buiten de habitatrichtlijnegebieden);

- $\quad$ een integratie met aanvullende datalagen (vnl. vegetatiekaarten, zie § 1.2.2);

\section{Gelieve bij gebruik van de kaarten steeds te refereren naar de gebruikte uitgave (zie colofon voor de referentie naar uitgave 2020). Voor internationale publicaties kan verwezen worden naar De Saeger et al. 2017.}




\subsection{Uitgave 2020}

\subsubsection{Beschikbaarheid}

Deze uitgave integreert de recentste informatie uit de BWK en de Natura 2000 habitatkaart. Ze vervangt alle vorige uitgaven, inclusief deze van 2018 (De Saeger et al. 2018).

De kaarten zijn voor iedereen online en interactief raadpleegbaar via het geoportaal van Geopunt Vlaanderen (www.geopunt.be). Bij opstart van de kaarttoepassing zie je rechts alle beschikbare kaarten. Voor het raadplegen van deze kaarten kies je in de keuzelijst eerst het thema 'Milieu en natuur', vervolgens 'Natuur' en dan de gewenste kaart. De 'Biologische waarderingskaart - versie 2' geeft de meest recente informatie weer; de 'versie 1' geeft een kaartbeeld uit de periode 1987- 1996. De kaartlagen verschijnen pas als je voldoende inzoomt. Via de zoekmogelijkheid boven de kaart, kan je snel op een gewenste gemeente of straat inzoomen. De respectievelijke kaartlabels behorende tot deze kaartlagen kunnen afzonderlijk aan- of uitgevinkt worden. De volledige informatie over een bepaald kaartvlak kan opgevraagd worden door er met de linkermuisknop op te klikken.

Gebruikers die zelf over GIS-software beschikken kunnen de kaarten (inclusief lookup-tabellen, legendes en rapporten) vrij downloaden via de Catalogus van Geopunt Vlaanderen of de downloadtoepassing van het Agentschap Informatie Vlaanderen (https://download.agiv.be/), of raadplegen via WMS. Op het internet zijn gratis GIS-programma's beschikbaar.

De ligging van de habitattypen 3260 (beken en rivieren met bepaalde waterplanten; Leysen et al. 2020) en 7220 (kalktufbronnen; Oosterlynck 2020) is integraal opgenomen in deze uitgave, maar voor specifieke toepassingen is tevens een afzonderlijk respectievelijk lijnen- en puntenbestand beschikbaar (zie referenties).

Het Natura 2000 habitattype 8310 (niet voor publiek opengestelde grotten) is niet opgenomen in deze kaart. In Vlaanderen komen geen natuurlijke grotten voor. De ondergrondse mergelgroeven in Zuid-Limburg hebben wel een typisch grottenklimaat. Deze die toegankelijk en geschikt zijn voor overwinterende vleermuizen, en niet in gebruik voor toegelaten menselijke activiteiten, zijn weerhouden als habitattype 8310 (De Saeger \& Lahaye 2019). Een GISlaag met de contouren van de mergelgroeven is afzonderlijk gepubliceerd (De Saeger et al. 2020).

\subsubsection{Actualisaties sinds uitgave 2018}

Sinds de vorige uitgave (De Saeger et al. 2018) zijn er door het BWK-veldteam van het INBO in 2018, 2019 en het voorjaar van 2020 opnieuw veldcampagnes uitgevoerd om de oudste karteringen te actualiseren (Figuur 1-1). Door een (tijdelijke) versterking van het vaste BWK-team is er een grote oppervlakte aan oude karteringen (2004 en ouder) geactualiseerd. Hierbij is er ruim 50.000 ha geactualiseerd via terreinbezoeken en ca. 110.000 ha via desktop controles (vnl. ALV 2017, ALV 2018, maar ook recente orthofoto's en Google Street View-beelden; cijfers excl. urbaan gebied). De prioriteit voor veldbezoeken lag daarbij binnen de habitatrichtlijngebieden (SBZ-H) (Figuren 1-2 en 1-3).

Daarnaast zijn ook enkele bestaande vegetatiekaarten vertaald naar de BWK- en habitattypologie, met als belangrijkste:

- $\quad$ vegetatiekartering (2013) van de Bovenzeeschelde en Durme (1.750 ha; Vandevoorde \& Van Lierop 2018);

- $\quad$ vegetatiekartering van het Zoniënwoud uit 2011 (2.138 ha; Roelandt 2012);

- $\quad$ vegetatiekartering van de bergenmeersen uit 2016 (Maris et al. 2016);

- vegetatiekartering van de IJzermonding uit 2018 (Vandevoorde et al. In voorbereiding).

De recentste verspreidingskaart van het Natura 2000 habitattype 3260 (Leysen et al. 2020) is nu ook integraal opgenomen en omgezet naar kaartvlakken. Ook het originele lijnenbestand is beschikbaar op geopunt.be en via de download (§ 1.2.1). Voor de habitattypen 7220 en 8310 zijn er ook afzonderlijke GIS-bestanden beschikbaar ( $\S$ 1.2.1).

De herkomsten 'luchtfoto' en 'literatuur' (zonder jaartal) in de figuren 1-1 en 1-2 dateren grotendeels van 19982000. Bij recentere karteringen en desktopcontroles worden deze herkomsten steeds voorzien van een herkomstjaar. In beide figuren wordt het urbaan gebied (ca. 348.000 ha, waarvan ca. 2.650 ha binnen SBZ-H) niet 
weergegeven. Veranderingen in het urbaan gebied (woon-, sport- en industriegebieden en transportwegen) worden hoofdzakelijk via luchtfotocontrole en de Basiskaart Vlaanderen (GRB) gedetecteerd.

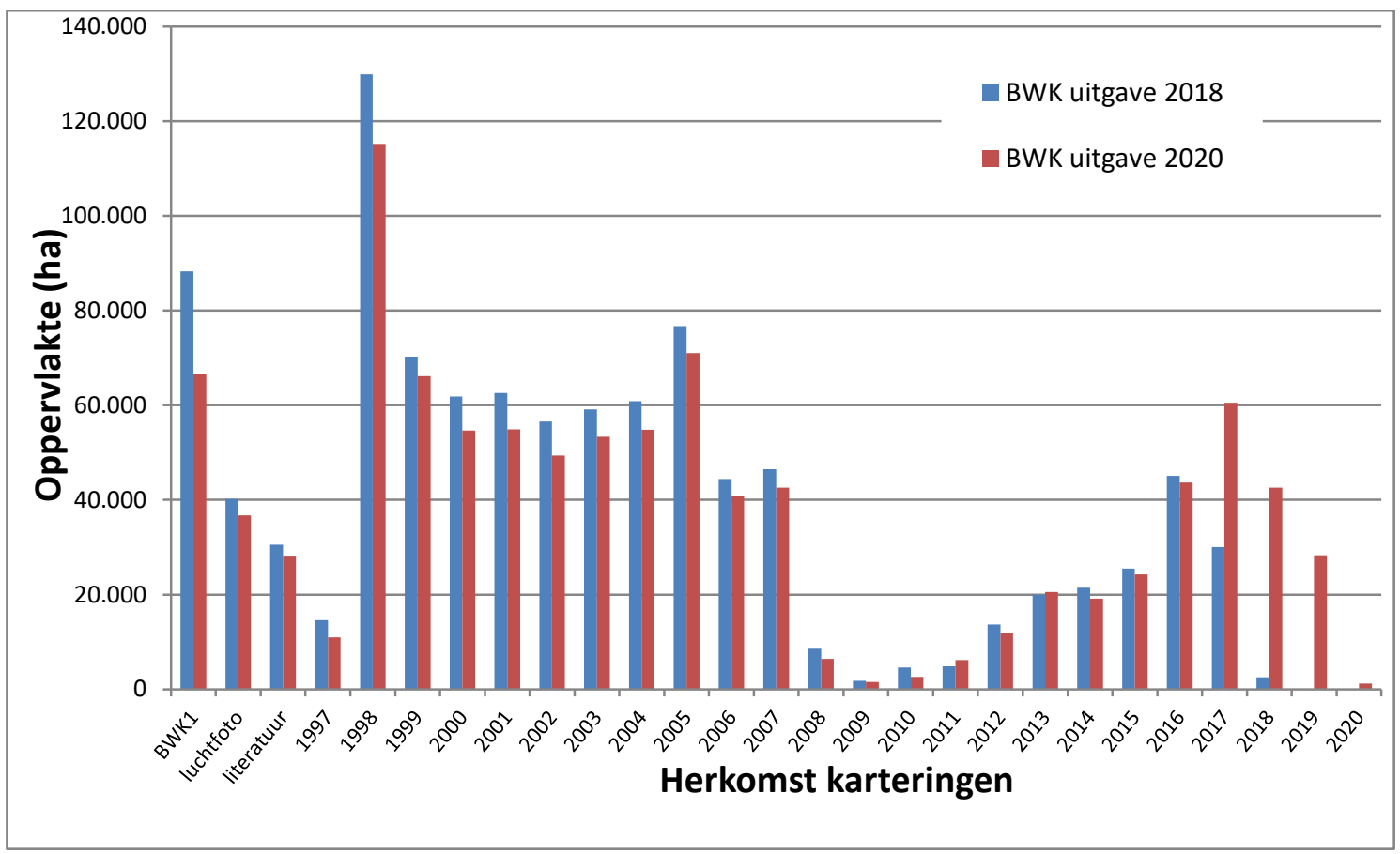

Figuur 1-1 Vergelijking tussen de herkomstperiode van BWK-habitatkaart uitgave 2018 en 2020 voor heel Vlaanderen, exclusief het urbaan gebied (zie § 2.1.3 voor duiding over de legende in de X-as).

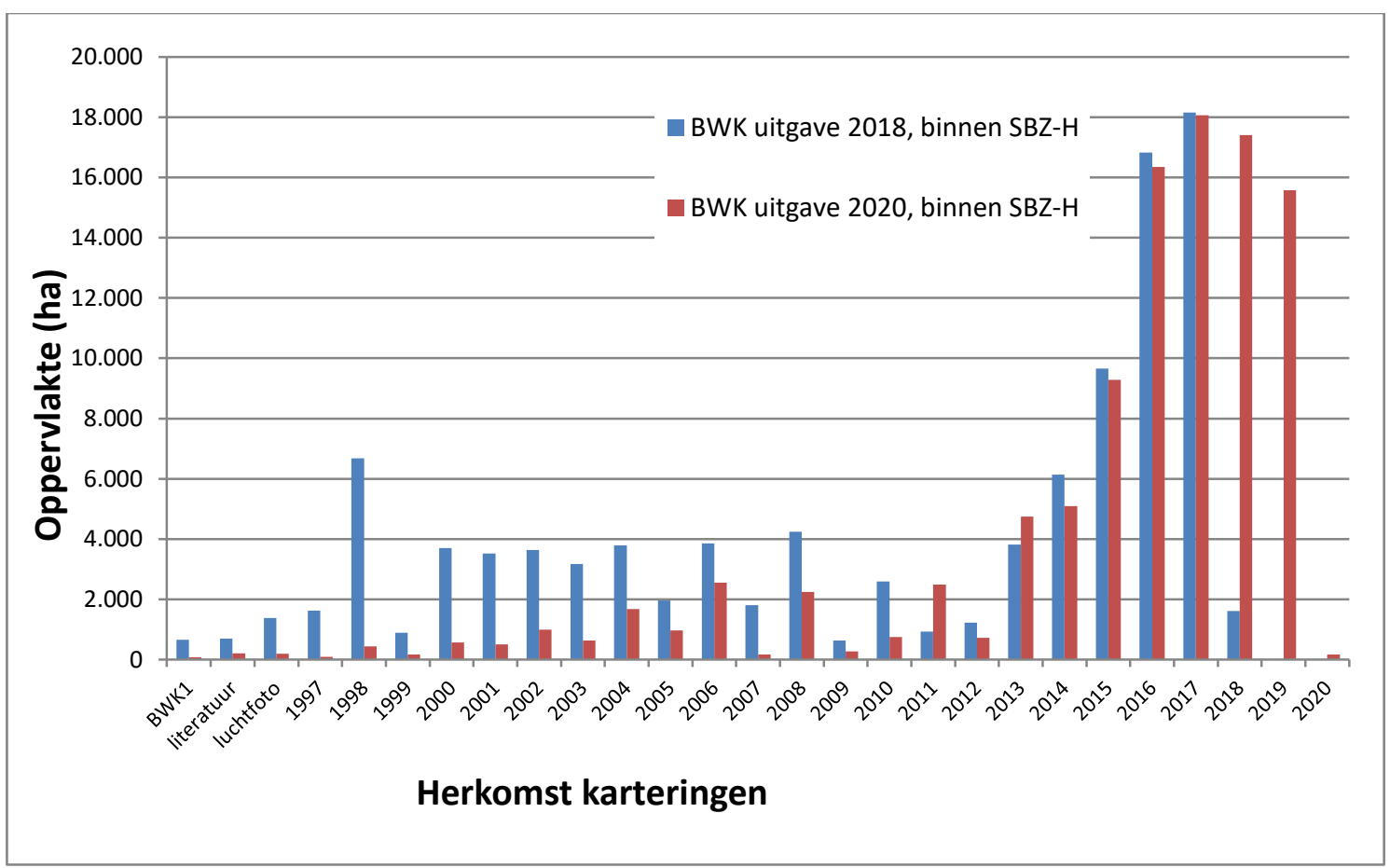

Figuur 1-2 Vergelijking tussen de herkomstperiode van BWK-habitatkaart uitgave 2018 en 2020 binnen de habitatrichtlijngebieden (SBZ-H), exclusief het urbaan gebied (zie $§ 2.1 .3$ voor duiding over de legende in de X-as). 
Figuur 1-3 geeft de ligging en ruimtelijke spreiding weer van de aanpassingen aan de BWK en habitatkaart sinds de uitgave in 2018. Er wordt onderscheid gemaakt tussen aanpassingen gebaseerd op terreinbezoek, aanpassingen gebaseerd op controle van recente luchtfoto's (vnl. Agentschap Informatie Vlaanderen, maar ook Google Street View en Beeldenbank Vlaanderen) en consultatie van de landbouwgebruikspercelen (vnl. ALV 2017, ALV 2018). Aanpassingen op basis van luchtfoto's hebben vooral betrekking op uitbreiding van het urbaan gebied, deze van de landbouwgebruikspercelen op uitbreiding van het areaal akkerland en tijdelijk grasland.

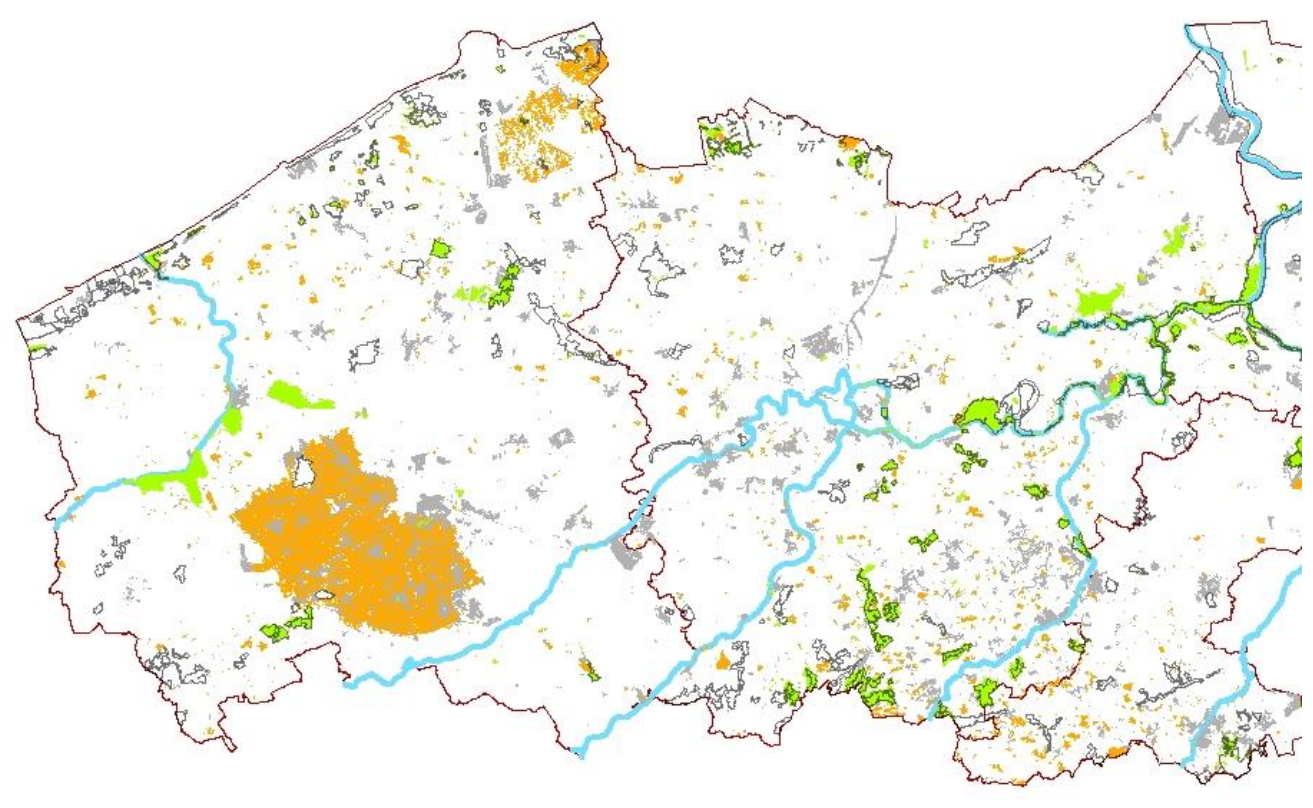




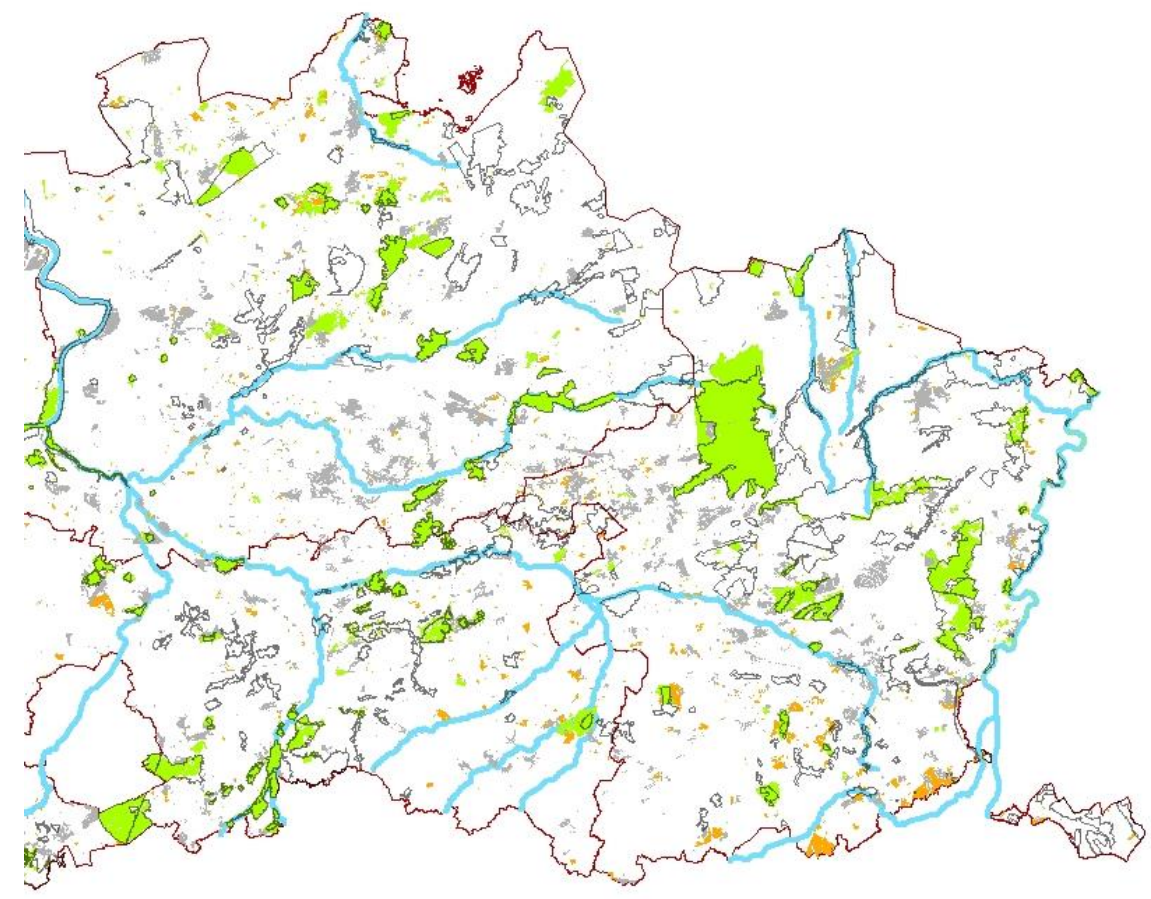

BWK - Habitatkaart uitgave 2020

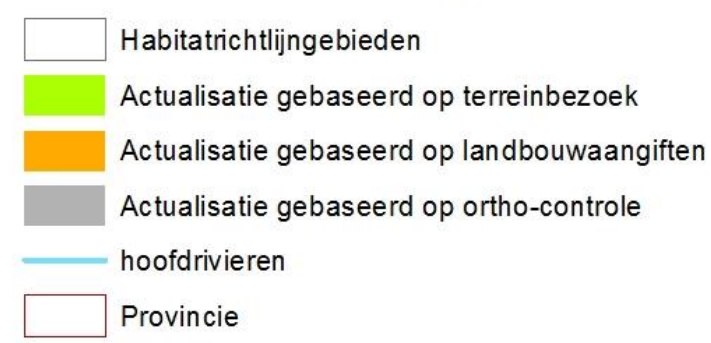

Figuur 1-3 Indicatie van de herkomst, ligging en ruimtelijke spreiding van de aanpassingen aan de BWK-habitatkaart 2020 sinds de publicatie van de vorige versie in 2018. 


\subsection{Karteringseenheden van de BWK}

De Biologische Waarderingskaart maakt gebruik van een vaste set karteringseenheden. De karteringseenheden zijn ingedeeld in grote klassen die ruwweg de bodembedekking beschrijven. Voor meer informatie over de BWKeenheden wordt verwezen naar Vriens et al. 2011, www.ecopedia.be en www.inbo.be/bwk.

De lijst van karteringseenheden is gebaseerd op een lijst uit 1979, opgesteld bij aanvang van het BWK-project. Ondertussen zijn er nieuwe inzichten verworven en indelingen gepubliceerd, zoals de Natura 2000 habitattypen (European Commission 2007) en de Vlaamse natuurtypen (weblink 2). Ook evolueerde de karteerschaal van een meer 'landschapsniveau' naar perceelsniveau of zelfs vegetatievlekniveau. In de jaren '90 zijn er bij de kleine landschapselementen bijkomende karteringseenheden toegevoegd voor lijnvormige vegetaties in de grasland-, moeras-, bos- en heidesfeer. Sinds de publicatie van BWK versie 2 (De Saeger et al. 2010, Vriens et al. 2011) is de methodiek verder geactualiseerd en verbeterd. Hierbij is ook de set van karteringseenheden onder de loep genomen zodat deze duidelijker gedefinieerd zijn en beter aansluiten bij de Vlaamse natuurtypen en Europese habitattypen ${ }^{1}$.

Sinds de uitgave 2016 werden enkele nieuwe (vooral nieuwe varianten van) karteringseenheden geïntroduceerd of duidelijker gedefinieerd. Ook in deze uitgave zijn er enkele aanpassingen aan de lijst met karteringseenheden ( $\S$ 1.3.1). Omdat nog niet iedereen vertrouwd is met de nieuwe (varianten van) eenheden, herhalen we deze die sinds uitgave 2016 in gebruik zijn ( $\$ 1.3 .2$ ).

LET OP: uitgave 2020 bestaat buiten de SBZ-gebieden nog steeds voor een groot deel uit karteringen van vóór 2014 (zie figuur 1-1 en 1-2). Voor de interpretatie van de kaarten dient men steeds aandacht te hebben voor de herkomst van een specifieke kartering. Dit is vooral essentieel voor karteringseenheden die voor en na 2014 dezelfde notatie behouden, maar een (licht) gewijzigde betekenis hebben. Dit geldt voor de eenheden $\boldsymbol{k j}, \boldsymbol{n}, \boldsymbol{s z}, \boldsymbol{a} \boldsymbol{e}$ en $\boldsymbol{a e r}$.

\subsubsection{Aanpassingen in uitgave 2020}

In deze uitgave van de BWK wordt een nieuwe karteringseenheid voor de typering van moerasvegetaties en enkele nieuwe varianten van bestaande karteringseenheden geïntroduceerd. Bij het herwerken van de karteerregels voor kleine landschapselementen zijn eveneens aanpassingen doorgevoerd in het gebruik van de karteringseenheid voor hoogstamboomgaarden (De Saeger et al. in voorbereiding). Deze worden vanaf nu steeds als grasland (of andere ondergroei) + hoogstam fruitbomen aangeduid (vb. $\boldsymbol{h} \boldsymbol{p}+\boldsymbol{k j}$ ) (Tabel 1-1; De Saeger et al. In voorbereiding). Deze nieuwe notatie is in deze uitgave met terugwerkende in de databank doorgevoerd. Dit impliceert dat voor het selecteren van kaartvlakken met hoogstamboomgaarden, de gebruiker vanaf uitgave 2020 enkel naar de eenheden 2 en 3 moet kijken. Voor selecties van hoogstamboomgaarden in oudere versie moet ook (en vooral) naar eenheid 1 gekeken worden. Deze nieuwe notatie maakt ook het zoeken naar (historisch) permanente graslanden met of zonder hoogstam fruitbomen makkelijker. Het graslandtype wordt nu steeds met eenheid 1 aangeduid.

Tabel 1-1 geeft een overzicht van de nieuwe en aangepaste karteringseenheden in deze uitgave. Door gebruik te maken van de informatie in de kolom 'verklaring' in deze tabel blijven vergelijkingen tussen de recentste uitgave en de vorige versies mogelijk. Voor een volledig overzicht van alle karteringseenheden verwijzen we naar de lookuptabel in de download bij het digitale bestand (zie § 1.2.1). Om de nieuwe typen op het terrein te determineren verwijzen we naar De Saeger et al. 2016a, De Saeger et al. 2016b, Vandekerkhove et al. 2016, Scheers et al. 2016 en De Saeger \& Wouters 2018.

Tabel 1-1 Overzicht van de 'nieuwe' karteringseenheden (KE) in BWK, uitgave 2020.

\begin{tabular}{|l|l|}
\hline $\boldsymbol{K} \boldsymbol{E}$ & Verklaring \\
\hline $\boldsymbol{m} \boldsymbol{j}$ & Dit zijn nieuwe karteringseenheden om moerasvegetaties gedomineerd door grote russen \\
$\boldsymbol{m} \boldsymbol{j} \boldsymbol{b}$ & (pitrus, zeegroene rus, biezenknoppen) aan te duiden (Oosterlynck et al. 2020). \\
$\boldsymbol{k}(\boldsymbol{m} \boldsymbol{j})$ & Vroeger werden dergelijke vegetaties gekarteerd als $\boldsymbol{h} \boldsymbol{j}$. De eenheid $\boldsymbol{h} \boldsymbol{j}$ blijft bestaan, maar \\
$\boldsymbol{k}(\boldsymbol{m} \boldsymbol{j} \boldsymbol{b})$ & staat bij recente karteringen (vanaf 2016) enkel nog voor graslanden. \\
\hline
\end{tabular}

\footnotetext{
${ }^{1}$ Met 'habitattype' wordt steeds een Natura 2000 habitattype bedoeld.
} 


\begin{tabular}{|c|c|}
\hline $\begin{array}{l}k j \\
k j^{\circ} \\
k j^{*}\end{array}$ & $\begin{array}{l}\text { Dit is geen nieuwe karteringseenheid, maar de aanduiding van een hoogstamboomgaard } \\
\text { gebeurd nu als een klein landschapselement zoals een poel of bomenrij, dus na eerst het } \\
\text { grasland (of andere begroeiing) te typeren, bijvoorbeeld } \boldsymbol{h} \boldsymbol{p}^{*}+\boldsymbol{k j} \\
\text { In oudere uitgaven werden hoogstamboomgaarden gekarteerd zonder vermelding van het } \\
\text { grasland (vb. } \boldsymbol{k} \text { ) of door de ondergroei met een slash-verhouding weer te geven (vb. } \\
\boldsymbol{k j} / \boldsymbol{h} \boldsymbol{p}^{*} \text { ). De nieuwe notatie is duidelijker qua leesbaarheid en eenvoudiger voor analyses } \\
\text { en selecties van (historisch) (permanent) grasland en hoogstamboomgaarden. }\end{array}$ \\
\hline$m m b$ & $\begin{array}{l}\text { Dit is een nieuwe variant van een bestaande karteringseenheid om verbossing in } \\
\text { galigaanmoeras }(\mathbf{m m}) \text { aan te duiden. }\end{array}$ \\
\hline $\begin{array}{l}k h(v o) \\
k h\left(v o^{\circ}\right) \\
k h\left(v o^{*}\right)\end{array}$ & $\begin{array}{l}\text { Dit zijn nieuwe varianten van een bestaande karteringseenheid vo om het voorkomen van } \\
\text { deze vegetatie als klein landschapselement aan te duiden. }\end{array}$ \\
\hline $\begin{array}{l}\text { sprb } \\
k h(s p r b) \\
k t(s p r b)\end{array}$ & 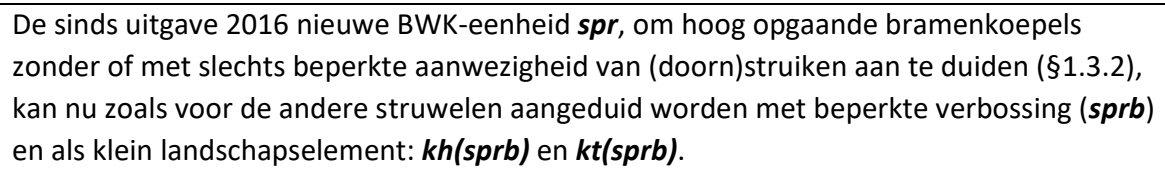 \\
\hline $\begin{array}{l}\text { k(hmo) } \\
k(h m o-) \\
k(h m o+)\end{array}$ & $\begin{array}{l}\text { Dit zijn nieuwe varianten van een bestaande karteringseenheid } \mathbf{h m o} \text { om het voorkomen } \\
\text { van deze vegetatie als klein landschapselement aan te duiden. }\end{array}$ \\
\hline
\end{tabular}

Waterlopen (karteringseenheid wat) kregen tot heden geen waardering. Dit dateerde nog van de periode dat de BWK enkel op gedrukte kaarten beschikbaar was en waterlopen een blauwe overdruk kregen. Vanaf uitgave 2020 is de waardering aangepast naar standaard 'biologisch waardevol' en voor de habitatwaardige waterlopen (habitat 3260) naar 'biologisch zeer waardevol'.

\subsubsection{Aanpassingen sinds uitgave 2016}

Sinds uitgave 2016 van de BWK zijn binnen de heide- en bosbiotopen enkele nieuwe karteringseenheden of varianten van bestaande karteringseenheden geïntroduceerd of zijn ze duidelijker gedefinieerd (meer info in De Saeger et al. 2016a en Vandekerkhove et al. 2016). Bij het herwerken van de biotoopgroep van de stilstaande wateren werden eveneens kleine aanpassingen doorgevoerd en werden de varianten van de karteringseenheden $\boldsymbol{a p}$ en $\boldsymbol{a} \boldsymbol{e}$ duidelijker gedefinieerd (Scheers et al. 2016). Bij de opmaak en herziening van de graslanden zijn 2 extra subtype bij de natte ruigten toegevoegd (De Saeger \& Wouters 2018). Tabel 1-2 geeft een overzicht van de nieuwe varianten en karteringseenheden sinds uitgave 2016. Door gebruik te maken van de informatie in de kolom 'verklaring' in deze tabel blijven vergelijkingen tussen de nieuwe versies en de BWK versie 2 mogelijk.

Tabel 1-2 Overzicht van de 'nieuwe' karteringseenheden (KE) in BWK, uitgave 2016.

\begin{tabular}{|c|c|}
\hline$K E$ & Verklaring \\
\hline $\begin{array}{l}\text { hac } \\
\text { hac }^{\circ} \\
\text { hac* }^{*}\end{array}$ & $\begin{array}{l}\text { Dit zijn nieuwe varianten van karteringseenheden voor vegetaties behorende tot het } \\
\text { buntgrasverbond (Corynephorion) aan te duiden. Deze ressorteerden vroeger onder ha (en deels } \\
\text { ook onder } \mathbf{d m} \text { ) (De Saeger et al. 2016a). }\end{array}$ \\
\hline $\begin{array}{l}\text { hat } \\
\text { hat }^{\circ} \\
\text { hat }^{*}\end{array}$ & $\begin{array}{l}\text { Dit zijn nieuwe varianten van karteringseenheden om vegetaties behorende tot het } \\
\text { dwerghaververbond (Thero-Airion) aan te duiden. Deze ressorteerden vroeger onder ha (De } \\
\text { Saeger et al. 2016a). }\end{array}$ \\
\hline$n i$ & $\begin{array}{l}\text { Dit is een nieuwe variant van een karteringseenheid voor jonge, recente loofhoutaanplanten. } \\
\text { Deze ressorteerde vroeger onder } \boldsymbol{n} \text { (dikwijls met vermelding van 'jonge aanplant' in het infoveld } \\
\text { van de BWK-databank) (Vandekerkhove et al. 2016). }\end{array}$ \\
\hline$n a$ & $\begin{array}{l}\text { Dit is een nieuwe variant van een karteringseenheid voor oude loofbossen met dikke bomen die } \\
\text { nog onvoldoende ontwikkeld of te sterk verstoord zijn om tot een bostype en/of habitattype te } \\
\text { rekenen (Vandekerkhove et al. 2016). Vroeger ressorteerden deze bossen grotendeels onder de } \\
\text { karteringseenheid } n \text {, maar deels ook onder } \boldsymbol{q} \boldsymbol{b}^{(\mathrm{o})} \text { (in de Kempen) en onder } \boldsymbol{q s ^ { ( \circ ) }} \text { (buiten de } \\
\text { Kempen). Deze laatste zijn dan o.a. oude }( \pm 80 \mathrm{j} \text { ) aanplanten van (Amerikaanse) eik met } \\
\text { weinig/geen bosplanten (Vriens et al. 2011). }\end{array}$ \\
\hline
\end{tabular}




\begin{tabular}{|c|c|}
\hline$n$ & $\begin{array}{l}\text { Deze karteringseenheid blijft bestaan voor 'jonge loofbossen', ongeacht het ontstaan en dus niet } \\
\text { enkel meer voor aangeplante loofbossen (Vandekerkhove et al. 2016). } \\
\text { Noot: de eenheden n, na, ni worden enkel benut voor bossen die niet te typeren zijn als inheemse } \\
\text { loofbossen (bosklassen } Q, F, R, V \text { ) en zijn exclusief populierenaanplanten. }\end{array}$ \\
\hline$s z$ & 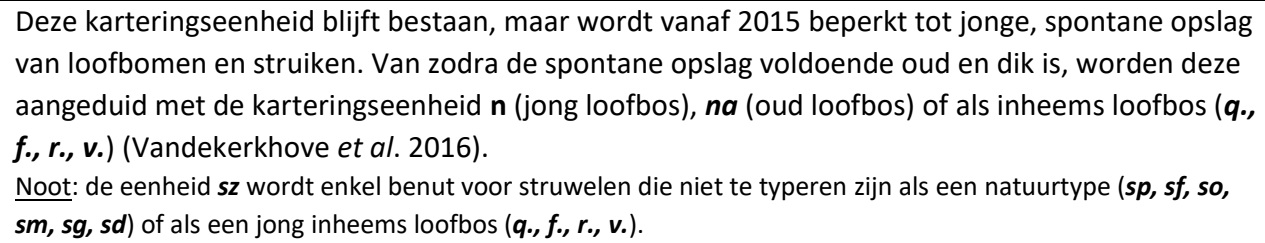 \\
\hline$v r$ & $\begin{array}{l}\text { Dit is een nieuwe karteringseenheid voor niet habitatwaardige essen-elzenbossen op een vallei- } \\
\text { of moerasbodem wegens een slechts beperkt aandeel oud-bosplanten of vochtindicatoren } \\
\text { (Vandekerkhove et al. 2016). Ze worden dikwijls gedomineerd door grote brandnetel, kleefkruid, } \\
\text { stekelvarens en/of gewone braam (bostypes D2 en D3 in Cornelis et al. 2009). Vroeger } \\
\text { ressorteerden deze bossen onder } \boldsymbol{v n}^{(0)}, \boldsymbol{n}+\boldsymbol{a l n g} \text { of } \boldsymbol{s z}+\boldsymbol{a l n g} \text {. }\end{array}$ \\
\hline $\begin{array}{l}\text { ppmc } \\
\text { ppmc* } \\
\text { pmc } \\
\text { pmc* }\end{array}$ & $\begin{array}{l}\text { Dit zijn nieuwe variant van een karteringseenheden voor naaldbossen met een kruidlaag } \\
\text { gedomineerd door struikhei, dophei en/of blauwe bosbes (Vandekerkhove et al. 2016). Vroeger } \\
\text { werden deze soms gekarteerd als } \mathbf{p p m} / \mathrm{cg} \text { of } \mathbf{p m} / \mathrm{cg} \text {. Deze notatie was verwarrend omdat het (in } \\
\text { de meeste gevallen) wel degelijk gaat over een normale bosondergroei en niet over een heide } \\
\text { onder bos. }\end{array}$ \\
\hline $\begin{array}{l}\text { ppmp } \\
\text { ppmp* } \\
\text { pmp } \\
\text { pmp* }\end{array}$ & $\begin{array}{l}\text { Dit zijn nieuwe variant van een karteringseenheden voor naaldbossen met een kruidlaag } \\
\text { gedomineerd door adelaarsvaren (Vandekerkhove et al. 2016). }\end{array}$ \\
\hline $\begin{array}{l}h f I^{\circ} \\
h f I^{\circ} \\
h f I^{*}\end{array}$ & $\begin{array}{l}\text { Dit zijn nieuwe variant van een karteringseenheden om 'zure, natte ruigten met grote wederik en } \\
\text { hennegras' aan te duiden. Vroeger werden deze gekarteerd als } \boldsymbol{h} f\left({ }^{\circ}\right) \text { en soms als } \boldsymbol{m s} \boldsymbol{s}^{\circ} \text {. } \\
\text { Meer info in De Saeger \& Wouters } 2018 .\end{array}$ \\
\hline $\begin{array}{l}\text { hfe } \\
\text { hfe } \\
\text { hfe* }\end{array}$ & $\begin{array}{l}\text { Dit zijn nieuwe variant van een karteringseenheden om vegetatie van het verbond van harig } \\
\text { wilgenroosje (Epilobion hirsuti) aan te duiden. Vroeger werden deze gekarteerd als } \boldsymbol{k} \boldsymbol{u}^{*} \text { of } \boldsymbol{h \boldsymbol { f } ^ { \circ } \text { . }} \\
\text { Meer info in De Saeger \& Wouters } 2018 .\end{array}$ \\
\hline $\begin{array}{l}\text { spr } \\
\text { sprb } \\
k h(s p r) \\
k h(s p r b) \\
k t(s p r) \\
k t(s p r b)\end{array}$ & $\begin{array}{l}\text { Dit zijn een nieuwe variant van een karteringseenheiden voor hoog opgaande bramenkoepels } \\
\text { zonder of met slechts beperkte aanwezigheid van (doorn)struiken (Vandekerkhove et al. 2016). } \\
\text { Vroeger ressorteerde deze (pionier)struweelfase onder } \boldsymbol{h} \boldsymbol{r b} \text { of } \boldsymbol{s p}^{\circ} \text {. }\end{array}$ \\
\hline$a e, a e r$ & $\begin{array}{l}\text { Deze karteringseenheden blijven bestaan, maar onderscheid duidt niet meer op oudere versus } \\
\text { recentere plassen, want dat was een vage grens die op terrein amper vast te stellen was. Bij } \\
\text { karteringen vanaf } 2014 \text { duiden deze KE op eutrofe plassen met kunstmatige of steile (aer) versus } \\
\text { natuurlijke oever (ae). In Scheers et al. } 2016 \text { wordt geduid hoe het onderscheid te maken. Dit } \\
\text { rapport bevat tevens duidelijke afspraken over het gebruik van de }{ }^{\circ} \text { en * in functie van } \\
\text { ontwikkelingsgraad van de submerse vegetatie. }\end{array}$ \\
\hline
\end{tabular}




\subsection{Natura 2000 habitattypen}

In Vlaanderen komen actueel 46 habitattypen van de Bijlage I van de Habitatrichtlijn met zekerheid voor (Paelinckx et al. 2019). Deze habitatkaart geeft de best beschikbare informatie anno 2020 weer van alle Natura 2000 habitattypen die in Vlaanderen voorkomen, behalve:

- $\quad$ habitattype 8310, niet voor publiek opengestelde grotten. De habitatkaart geeft immers enkel de bovengrondse typering weer. In Vlaanderen komen geen natuurlijke grotten voor. De ondergrondse mergelgroeven in Zuid-Limburg hebben wel een typisch grottenklimaat. Deze die toegankelijk en geschikt zijn voor overwinterende vleermuizen worden weerhouden als habitattype 8310 (De Saeger \& Lahaye 2019). Een GIS-laag met de contouren van de mergelgroeven is afzonderlijk gepubliceerd (De Saeger et al. 2020).

Voor een volledig overzicht van alle habitatcodes verwijzen we naar de lookup-tabel in de download bij het digitale bestand (zie § 1.2.1).

Enkele habitattypen zijn nog steeds deels of grotendeels als 'onzeker habitat' opgenomen in de habitatkaart:

- habitattype 6430: de verspreiding van het subtype moerasspireaverbond (6430_hf) zit nog voor een groot deel als 'onzeker habitat' (kennislacune) in de kaart (code 6430,rbbhf), door onzekerheid bij de vertaalslag vanuit de BWK-eenheid $\boldsymbol{h} \boldsymbol{f}$

- habitattype 6430: de verspreiding van één van de subtypen, de boszomen (6430_bz), is slechts ten dele gekend en dus slechts in beperkte mate uit de habitatkaart af te leiden.

Bij herkarteringen worden deze kennislacunes opgelost.

Voor een algemene beschrijving van de Natura 2000 habitattypen verwijzen we naar Decleer et al. 2007 of www.ecopedia.be. Voor een juiste typering op het terrein verwijzen we naar de veldsleutels: De Saeger et al. 2016a, De Saeger et al. 2016b, Vandekerkhove et al. 2016, Scheers et al. 2016, De Saeger \& Wouters 2018, Oosterlynck et al. (in voorbereiding) en De Saeger et al. (in voorbereiding) (Weblink 3).

Sinds de vorige versie van de habitatkaart (De Saeger et al. 2018) is het aandeel kennislacunes (onzekere habitatbepalingen) in de habitatcodes verder gedaald. Door recent veldwerk is dit vooral binnen de habitatrichtlijngebieden merkbaar (Tabel 1-3). De oppervlakte aan kennislacunes zoals in de tabel vermeld, is een indicatie en een overschatting, omdat dikwijls slechts een deel van een kaartvlak als 'onzeker' is aangeduid.

De meeste kennislacunes in de huidige kaart hebben nog te maken met (semi-)automatische vertaalslagen van oudere BWK-karteringen naar habitattypen (vnl. karteringen van vóór 2004). Dikwijls betreft het onzekerheid over de actuele graad van verbossing in van nature open habitattypen of over het al dan niet habitatwaardig zijn van moerasspirearuigten (hf), glanshavergraslanden $(\boldsymbol{h u})$ of diepe wateren (ap).

Tabel 1-3 Indicatieve vergelijking tussen BWK-habitatkaart uitgave 2018 en 2020 wat betreft de oppervlakte aan polygonen die als kennislacune zijn aangeduid (code 'ohab' in de Habitat-legende).

\begin{tabular}{|l|r|r|}
\cline { 2 - 3 } \multicolumn{1}{c|}{} & $\begin{array}{l}\text { BWK uitgave } \\
\text { 2018, opp (ha) }\end{array}$ & $\begin{array}{l}\text { BWK uitgave } \\
\text { 2020, opp (ha) }\end{array}$ \\
\hline $\begin{array}{l}\text { polygonen die mogelijk een } \\
\text { habitattype bevatten } \\
\text { (kennislacunes): }\end{array}$ & 11.800 & 8.700 \\
\hline
\end{tabular}

\begin{tabular}{|r|l|}
\hline $\begin{array}{r}\text { BWK uitgave 2018, in } \\
\text { SBZ-H, opp. (ha) }\end{array}$ & $\begin{array}{l}\text { BWK uitgave 2020, in } \\
\text { SBZ-H, opp. (ha) }\end{array}$ \\
\hline 1.700 & \\
\hline
\end{tabular}

\subsection{Regionaal belangrijke biotopen}

Regionaal belangrijke biotopen (rbb) zijn:

- $\quad$ biotopen die naar biologische waarden en belang voor de biodiversiteit vergelijkbaar zijn met habitattypen, maar die op Europees niveau niet beschermd zijn en daardoor niet zijn toegevoegd aan de lijst van Europees beschermde Natura 2000 habitattypen (regionaal belangrijke biotopen behoren vaak wel tot het leefgebied van een Europees beschermde soort in uitvoering van de Habitat- of Vogelrichtlijn).

- $\quad$ EN die een Vlaamse bescherming genieten in uitvoering van het Natuur- en/of Bosdecreet. 
In de wetteksten zijn ze nagenoeg allemaal geformuleerd in termen van de karteringseenheden van de Biologische Waarderingskaart, zodat hun ligging meestal grotendeels af te leiden is uit de Biologische Waarderingskaart. In recente (ontwerp) wet- en beleidsteksten wordt echter rechtstreeks verwezen naar de rbb-codes. Vriens et al. (2011) geven een omstandige beschrijving. Verdere beschrijvingen zijn te vinden in de Vlaamse Natuurtypen (Weblink 2), al is daarin de term 'regionaal belangrijk biotoop' niet vermeld.

De attribuutvelden met betrekking tot de habitattypering bevatten de indicatieve situering van de meeste regionaal belangrijke biotopen (Tabel 1-4). Volgende rbb's zijn slechts deels opgenomen in de kaartlaag omdat ze niet rechtstreeks uit de karteringseenheden van de Biologische Waarderingskaart zijn af te leiden:

- $\quad$ zilverschoongrasland (rbbzil), soortenrijk kamgrasgrasland (rbbkam) en soortenrijke grote vossenstaartgraslanden (rbbvos) (vallen alle grotendeels onder soortenrijk permanent cultuurgrasland $\boldsymbol{h} \boldsymbol{p}^{*}$ en $\boldsymbol{h} \boldsymbol{p} \boldsymbol{r}^{*}$, maar differentiatie naar het rbb-type kan enkel via terreinbezoek)

- moerasspirearuigte met graslandkenmerken (rbbhf) is nog niet volledig rechtstreeks uit de BWK-eenheid af te leiden en zit nog voor een deel als 'onzeker habitat', code 6430,rbbhf in de databank.

- Structuurrijke, oude bestanden van grove den (rbbppm)

- $\quad$ soortenrijke, niet habitatwaardige struisgrasvegetatie (rbbha)

In karteringen vanaf 2014 worden deze kennislacunes opgelost.

Tabel 1-4 Regionaal belangrijke biotopen in Vlaanderen in de habitatkaart, uitgave 2020

\begin{tabular}{|c|c|c|c|}
\hline \multirow[t]{2}{*}{ Code } & \multirow[t]{2}{*}{ Naam } & \multicolumn{2}{|c|}{ Habitatkaart 2020} \\
\hline & & In SBZ-H & Buiten SBZ-H \\
\hline rbbah & brak of zilt water & ja & ja \\
\hline rbbhc & dotterbloemgrasland & ja & ja \\
\hline rbbha & soortenrijke, niet habitatwaardige struisgrasvegetatie & grotendeels & deels \\
\hline rbbzil & $\begin{array}{l}\text { zilverschoongrasland (valt onder soortenrijk permanent } \\
\text { cultuurgrasland } \boldsymbol{h} \boldsymbol{p}^{*} \text { en } \boldsymbol{h} \boldsymbol{p} \boldsymbol{r}^{*} \text { ) }\end{array}$ & grotendeels & deels \\
\hline rbbkam & $\begin{array}{l}\text { soortenrijk kamgrasland (valt onder soortenrijk permanent } \\
\text { cultuurgrasland } \boldsymbol{h} \boldsymbol{p}^{*} \text { en } \boldsymbol{h} \boldsymbol{p} \boldsymbol{r}^{*} \text { ) }\end{array}$ & grotendeels & $\begin{array}{l}\text { deels } \\
\text { (vnl. in de } \\
\text { kustpolders) }\end{array}$ \\
\hline rbbvos & $\begin{array}{l}\text { grote vossenstaartgrasland, indien niet vervat in } \\
\text { habitattype } 6510 \text { (valt onder soortenrijk permanent } \\
\text { cultuurgrasland } \boldsymbol{h} \boldsymbol{p}^{*} \text { en } \boldsymbol{h} \boldsymbol{p} \boldsymbol{r}^{*} \text { ) }\end{array}$ & $\begin{array}{l}\text { deels (vnl. recente } \\
\text { karteringen) }\end{array}$ & $\begin{array}{l}\text { deels (vnl. recente } \\
\text { karteringen } \\
\text { IJzervallei) }\end{array}$ \\
\hline rbbhf & $\begin{array}{l}\text { moerasspirearuigte met graslandkenmerken (en daardoor } \\
\text { niet behorend tot habitattype 6430) }\end{array}$ & grotendeels & deels \\
\hline rbbmr & rietland en andere vegetaties van het rietverbond & ja & ja \\
\hline rbbmc & grote zeggenvegetatie & ja & ja \\
\hline rbbms & kleine zeggenvegetatie niet vervat in overgangsveen (7140) & ja & ja \\
\hline rbbppm & structuurrijk, oud bestand van grove den & klein deel & klein deel \\
\hline rbbsg & brem- en gaspeldoornstruweel & ja & ja \\
\hline rbbsm & gagelstruweel & ja & ja \\
\hline rbbso & vochtig wilgenstruweel op venige of zure grond & ja & ja \\
\hline rbbsp & doornstruweel & ja & ja \\
\hline rbbsf & moerasbos van breedbladige wilgen & ja & ja \\
\hline
\end{tabular}




\section{Attribuutvelden van BWK en habitatkaart}

\subsection{Attribuutvelden met de informatie van de Biologische Waarderingskaart}

\begin{tabular}{|l|l|l|l|l|l|l|}
\hline TAG & EVAL & EENH1, ... EENH8 & V1, V2, V3 & HERK_BWK & INFO & BWKLABEL \\
\hline $\begin{array}{l}\text { uniek } \\
\text { nummer } \\
\text { voor elk } \\
\text { kaartvlak }\end{array}$ & waardering & $\begin{array}{l}\text { karteringseenheden } \\
\text { van de BWK }\end{array}$ & $\begin{array}{l}\text { aanduiding } \\
\text { van de /- } \\
\text { verhouding }\end{array}$ & $\begin{array}{l}\text { herkomst van } \\
\text { de kartering }\end{array}$ & $\begin{array}{l}\text { bijkomende } \\
\text { informatie die } \\
\text { in de BWK } \\
\text { wordt } \\
\text { weergegeven }\end{array}$ & $\begin{array}{l}\text { Aanduiding van } \\
\text { de volledige } \\
\text { BWK-typering } \\
\text { van het kaartvlak }\end{array}$ \\
\hline
\end{tabular}

In onderstaande paragrafen wordt kort ingegaan op de betekenis van deze velden.

\subsubsection{Attribuutveld EVAL}

Aan elke karteringseenheid wordt een bepaald 'biologisch' waardeoordeel toegekend. Complexen van karteringseenheden kunnen een gemengde waardering krijgen. Voor /-verhoudingen worden specifieke regels gehanteerd (voor meer info zie Vriens et al. 2011).

Tabel 2-1 Betekenis van de codes van het attribuutveld EVAL van de BWK

\begin{tabular}{|c|c|c|}
\hline Waardering & $\begin{array}{l}\text { Aanduiding in digitaal } \\
\text { bestand (EVAL) }\end{array}$ & $\begin{array}{l}\text { Aanbevolen aanduiding } \\
\text { via inkleuring }\end{array}$ \\
\hline Biologisch zeer waardevol & $z$ & \\
\hline Biologisch waardevol & w & \\
\hline Biologisch minder waardevol & $\mathrm{m}$ & \\
\hline $\begin{array}{l}\text { Complex van biologisch waardevolle en zeer } \\
\text { waardevolle elementen }\end{array}$ & wz & \\
\hline $\begin{array}{l}\text { Complex van biologisch minder waardevolle, } \\
\text { waardevolle en zeer waardevolle elementen }\end{array}$ & $\mathrm{mwz}$ & \\
\hline $\begin{array}{l}\text { Complex van biologisch minder waardevolle en } \\
\text { zeer waardevolle elementen }\end{array}$ & $\mathrm{mz}$ & \\
\hline $\begin{array}{l}\text { Complex van biologisch minder waardevolle en } \\
\text { waardevolle elementen }\end{array}$ & $\mathrm{mw}$ & \\
\hline
\end{tabular}

\subsubsection{Attribuutvelden EENH1 tot EENH8 en V1, V2, V3}

De inventarisatie van de Biologische Waarderingskaart gebeurt aan de hand van een vooraf bepaalde set karteringseenheden (velden EENH). Voor een volledig overzicht van de karteringseenheden verwijzen we naar Vriens et al. 2011 of www.inbo.be/bwk.

De velden V1, V2 en V3 duiden op een eventuele relatie (/-verhouding) tussen de karteringseenheden (bv. V1=12 staat voor EENH1/EENH2). De relatie wijst op een evolutie van de ene (EENH2) naar de andere (EENH1) karteringseenheid en/of geeft weer dat EENH2 voorkomt onder EENH1. Het /-teken wijst dus op successie en/of op gelaagdheid (voor meer info zie Vriens et al. 2011).

De notatie van enkele BWK-symbolen in het GIS-bestand vertoont omwille van technische redenen verschillen met deze in publicaties (Tabel 2-2; zie Vriens et al. 2011 voor meer informatie). 
Tabel 2-2 Voorbeelden van de belangrijkste verschillen in de notatie van de karteringseenheden (KE) in de digitale bestanden en in publicaties.

\begin{tabular}{|l|l|l|}
\hline & Digitaal bestand & Notatie in publicaties \\
\hline goed ontwikkeld en/of veel voorkomend & $\mathbf{k e +}$ & $\boldsymbol{k e}^{*}$ \\
\hline zwak ontwikkeld en/of weinig voorkomend & $\mathbf{k e -}$ & $\boldsymbol{k e}^{\circ}$ \\
\hline ontstaan uit, of in ondergroei van, bv. EENH1 t.o.v. EENH2 & $\mathbf{1 2}$ & $\mathbf{E E N H 1 / E E N H 2 ~}$ \\
\hline
\end{tabular}

\subsubsection{Attribuutveld HERK}

De gebruiker kan uit het veld HERK afleiden in welke maand en jaar een terreinbezoek plaatsvond, dan wel of de typologie bepaald is op basis van luchtfoto-interpretatie, gegevens uit andere studies of informatie verstrekt door bijvoorbeeld externe experten. De herkomst geeft een indicatie over de bron en actualiteitswaarde van de typologie van een gebied of perceel.

Tabel 2-3 Betekenis van de codes van het attribuutveld HERK van de BWK

\begin{tabular}{|c|c|}
\hline \multicolumn{2}{|c|}{ HERK: herkomst van de gegevens in de BWK } \\
\hline $\begin{array}{l}\text { bv. } 98 z, 085 \text {, } \\
125\end{array}$ & $\begin{array}{l}\text { Jaartal + maand of jaartal + voorjaar, zomer, herfst of winter; } \\
\text { bv. } 125 \text { staat voor 'gekarteerd in mei } 2012 \text { '. }\end{array}$ \\
\hline I & $\begin{array}{l}\text { Kartering op basis van literatuur of (interpretatie van) een ander digitaal bestand; soms } \\
\text { voorafgegaan door het jaartal van de waarneming of van de publicatie. }\end{array}$ \\
\hline ex, jaartalex & $\begin{array}{l}\text { Karteringen aangereikt door externe experten; soms voorafgegaan door het jaartal waarin de } \\
\text { kartering gebeurde. }\end{array}$ \\
\hline o, jaartalo & $\begin{array}{l}\text { Kartering gebaseerd op luchtfoto-interpretatie; sinds } 2009 \text { wordt deze code voorafgegaan door } \\
\text { het jaartal van de luchtfoto-opname waarop de typering is gebaseerd. }\end{array}$ \\
\hline $\mathrm{ob}$ & $\begin{array}{l}\text { Kartering overgenomen uit BWK versie } 1 \text { na kritische evaluatie via orthofoto- en/of } \\
\text { stafkaartinterpretatie (deze herkomstbron is vooral in de periode } 1997-2000 \text { gebruikt). }\end{array}$ \\
\hline
\end{tabular}

\subsubsection{Attribuutveld INFO}

Het infoveld kan extra informatie geven over de kartering, waardering of herkomst van het kaartvlak. Dit attribuutveld bevat zowel vooraf gecodeerde (bv. hpriv) als vrij door de karteerder te bepalen formuleringen. De toevoeging in het attribuutveld "info" zijn echter niet overal even stelselmatig gebeurd.

Voorbeelden van veel voorkomende vermeldingen in het attribuutveld "info":

- $\quad$ bij hp- en hx-graslanden die palen aan een rivier met een goede structuur of een goede waterkwaliteit (Bervoets et al. 1991, 1993 en 1996), wordt resp. 'hpriv' en 'hxriv' vermeld omdat dit tevens de verklaring is voor een eventuele opwaardering tot een "complex van minder waardevolle en waardevolle elementen";

- $\quad$ bij percelen die niet betreden konden worden, geeft de toevoeging 'op afstand gezien' of 'vanaf de rand gezien' aan dat men toch vrij zeker is van de typologie (maar minder zeker dan wanneer een perceel doorlopen is). Dergelijke polygonen krijgen 'veldwerk' als herkomst (bv. 064); indien men minder zeker was, kregen dergelijke percelen 'o' (orthofoto-interpretatie) als herkomst;

- $\quad$ verantwoording voor een afwijkende biologische waardering (bv. z < ...);

- $\quad$ verduidelijking van of uitleg over een karteringseenheid of een zgn. /-verhouding (attribuutvelden V1, V2, V3);

- $\quad$ verduidelijkingen over de herkomst;

- $\quad$ aanduiding dat het om biotopen op een 'veldweg', 'spoorwegberm' of '(snel)wegberm' gaat;

- $\quad$ aanduiding dat het betreffende biotoop door recente inrichtingswerken nog in ontwikkeling is en de kartering mogelijk snel gedateerd kan zijn, bv. 'natuurontwikkeling', 'plagplek',...

- $\quad$ vroegere toestand als het een wijziging betreft waarvan de vroegere situatie gedocumenteerd is; 


\subsection{Attribuutvelden met de informatie over de Natura 2000 habitattypen en de regionaal belangrijke biotopen}

\begin{tabular}{|c|c|c|c|c|}
\hline HAB1 ... HAB5 & PHAB1 ... PHab5 & HERK_HAB & HERK_PHAB & HABLEGENDE \\
\hline $\begin{array}{l}\text { habitatcodes of codes } \\
\text { van de regionaal } \\
\text { belangrijke biotopen }\end{array}$ & $\begin{array}{l}\text { oppervlakteaandeel } \\
\text { (\%) van elke } \\
\text { (habitat)code } \\
\text { binnen het vlak }\end{array}$ & $\begin{array}{l}\text { herkomst } \\
\text { habitatcodes }\end{array}$ & $\begin{array}{l}\text { herkomst } \\
\text { oppervlakteaandeel } \\
\text { van de (habitat)codes }\end{array}$ & $\begin{array}{l}\text { aanduiding voor } \\
\text { het al dan niet } \\
\text { aanwezig zijn van } \\
\text { een habitattype }\end{array}$ \\
\hline
\end{tabular}

In onderstaande paragrafen wordt kort ingegaan op de betekenis van deze velden.

\subsubsection{Attribuutvelden HAB1 tot HAB5}

Aanduiding van het Natura 2000 habitattype, het regionaal belangrijk biotoop of 'geen habitat' (gh). Soms is het juiste habitattype of regionaal belangrijk biotoop niet gekend of onzeker en kunnen meerdere codes gecombineerd worden in één veld. Dit komt voor bij percelen waarvan de habitattypologie is afgeleid uit de BWK-kartering en waarbij een voldoende eenduidige relatie ontbreekt. Voor een volledig overzicht van alle habitatcodes verwijzen we naar de lookup-tabel in de download bij het digitale bestand (zie § 1.2.1).

\subsubsection{Attribuutvelden PHAB1 tot PHAB5}

Deze velden geven het procentueel oppervlakteaandeel van het habitattype, de regionaal belangrijke biotoop of 'geen habitat' uit het overeenkomstige HAB-veld t.o.v. het geheel van het kaartvlak.

Indien 1 kaartvlak slechts 1 habitattype bevat is dit veld logischerwijs $=100 \%$. Van zodra er meerdere habitatcodes voorkomen, geeft dit veld het \%-oppervlakteaandeel van elke habitatcode in het kaartvlak weer. De som van de PHAB-velden is per kaartvlak normalerwijze gelijk aan 100\%. Enkel bij het habitattype 1130 (estuarium) kan dit hoger liggen omdat dit habitattype het volledige buitendijkse gebied (steeds $100 \%$ type 1130 ) omvat. Daarbinnen kunnen dan nog polygonen met specifieke habitattypen (vb. 1330_da, 91E0_sf) voorkomen.

Indien de waarden in de PHAB-velden het resultaat zijn van een 'automatische verdeling' (zie § 2.2.4), is het weergegeven procentueel aandeel een theoretisch verwacht aandeel, afgeleid uit de plaats van de overeenkomstige karteringseenheid van de BWK. Zulk theoretisch verwacht aandeel kan (lokaal) sterk verschillen van de realiteit op terrein.

\subsubsection{Attribuutveld HERK_HAB}

Dit veld geeft de gebruikte methode weer voor het bepalen van het habitattype, regionaal belangrijk biotoop of 'geen habitat'.

\begin{tabular}{|l|l|}
\hline \multicolumn{2}{|l|}{ HERK_HAB: herkomst van de habitatbepaling } \\
\hline bv. 085, 125 & $\begin{array}{l}\text { Habitattype op terrein bepaald } \\
\text { Jaartal + maand of jaartal + voorjaar, zomer, herfst of winter } \\
\text { Bv. 085 staat voor 'habitattype bepaald in mei 2008' }\end{array}$ \\
\hline a & automatische vertaling vanuit de BWK-kartering (zie Paelinckx et al. 2009) \\
\hline mk & manuele aanpassing van de automatische vertaling door de karteerder \\
\hline o & $\begin{array}{l}\text { automatische vertaling aangepast op basis van orthofoto-interpretatie; voorafgegaan door het } \\
\text { jaartal (en maand) van de luchtfoto-opname }\end{array}$ \\
\hline I & $\begin{array}{l}\text { habitattypering gebaseerd op literatuurgegevens of (interpretatie van) een ander digitaal } \\
\text { bestand; soms voorafgegaan door het jaartal van waarneming of de publicatie }\end{array}$ \\
\hline ex & $\begin{array}{l}\text { habitattypering aangereikt door externe experten; soms voorafgegaan door het jaartal waarin } \\
\text { de typering door de expert werd vastgesteld }\end{array}$ \\
\hline
\end{tabular}




\subsubsection{Attribuutveld HERK_PHAB}

Dit veld geeft de gebruikte methode weer voor het bepalen van het aandeel van elk habitattype, regionaal belangrijk biotoop of 'geen habitat' binnen een complex.

\begin{tabular}{|c|c|}
\hline \multicolumn{2}{|c|}{ HERK_PHAB: methode van de bepaling van het procentueel aandeel van elk habitattype } \\
\hline $\begin{array}{l}\text { bv. } 085, \\
125\end{array}$ & $\begin{array}{l}\text { Aandeel van elk habitattype op terrein bepaald } \\
\text { Jaartal + maand of jaartal + voorjaar, zomer, herfst of winter }\end{array}$ \\
\hline a & $\begin{array}{l}\text { automatische verdeling: toepassing van een vooraf gedefinieerde verdeelsleutel in functie van } \\
\text { het aantal habitattypen in het kaartvlak (Tabel } 2-4 \text { ), deze kan echter sterk verschillen van de } \\
\text { realiteit op terrein }\end{array}$ \\
\hline mk & manuele aanpassing van de automatische verdeling door de karteerder \\
\hline o & $\begin{array}{l}\text { aanpassing van de automatische verdeling op basis van orthofoto-interpretatie; soms } \\
\text { voorafgegaan door het jaartal van de luchtfoto-opname }\end{array}$ \\
\hline I & $\begin{array}{l}\text { aanpassing van de automatische verdeling op basis van literatuurgegevens; soms voorafgegaan } \\
\text { door het jaartal van de publicatie }\end{array}$ \\
\hline ex & $\begin{array}{l}\text { aanpassing van de automatische verdeling op basis van gegevens aangereikt door externe } \\
\text { experten; soms voorafgegaan door het jaartal waarin de gegevens werden aangereikt }\end{array}$ \\
\hline
\end{tabular}

Tabel 2-4 Automatische verdeelsleutel voor complexen van habitattypen bij automatische vertaling uit de BWK-kartering

\begin{tabular}{|l|l|}
\hline $\begin{array}{l}\text { Aantal karteringseenheden in de BWK attribuutvelden } \\
\text { (b) }\end{array}$ & $\begin{array}{l}\text { Automatische verdeelsleutel voor de PHAB- } \\
\text { attribuutvelden }\end{array}$ \\
\hline Enkel EENH1 & $100 \%$ \\
\hline EENH1 + EENH2 & $70 \%+30 \%$ \\
\hline EENH1+ EENH2+ EENH3 & $60 \%+20 \%+20 \%$ \\
\hline EENH1+ EENH2+EENH3 + EENH4 & $60 \%+20 \%+10 \%+10 \%$ \\
\hline EENH1+ EENH2+EENH3 + EENH4 + EENH5 & $\begin{array}{l}60 \%+20 \%+10 \%+10 \% \\
\text { (m.a.w. aan EENH5 en volgende wordt geen } \\
\text { oppervlakte meer toegekend) }\end{array}$ \\
\hline $\begin{array}{l}\text { EENH1+ EENH2+ EENH3 + EENH4 + EENH5 + EENH6 ... } \\
\text { EENH8 }\end{array}$ & \\
\hline
\end{tabular}
Opmerkingen:

(a) Merk op dat de percentages worden toegekend op basis van het aantal karteringseenheden in de attribuutvelden van het BWK-deel EN DUS NIET op basis van het aantal ingevulde HAB-velden;

(b) de kleine landschapselementen worden, als ze al habitat of regionaal belangrijk biotoop zijn, in de oppervlaktebepaling niet in rekening gebracht (ze worden dus niet als 'EENHx' beschouwd; tenzij ze als afzonderlijk kaartvlak zijn uitgedigitaliseerd); dit geldt niet voor dijken, voormalige spoorwegbermen, ...

\subsubsection{Attribuutveld HABLEGENDE}

Dit veld geeft per kaartvlak (polygoon) aan of er al dan niet een Natura 2000 habitattype aanwezig is.

\begin{tabular}{|c|c|}
\hline Code & Verklaring \\
\hline gh & $\begin{array}{l}\text { Geen Natura } 2000 \text { habitattype aanwezig. } \\
\text { Noot: de afwezigheid van een Europees habitattype betekent niet dat dergelijke polygonen geen (zeer) } \\
\text { waardevolle biotopen kunnen bevatten. Controleer hiervoor de BWK-velden (§ 2.1.2) en het al dan niet } \\
\text { aanwezig zijn van een regionaal belangrijk biotoop in de HAB-velden (§ } 2.2 .1 \text {. }\end{array}$ \\
\hline hab & $\begin{array}{l}\text { Habitat, het volledige kaartvlak is habitatwaardig. Er kunnen één of meer habitattypen } \\
\text { voorkomen. }\end{array}$ \\
\hline phab & $\begin{array}{l}\text { Deels (partieel) habitat, het kaartvlak bevat zowel habitatwaardige, als niet habitatwaardige } \\
\text { delen. }\end{array}$ \\
\hline ohab & $\begin{array}{l}\text { Onzeker habitat (kennislacune): het kaartvlak is mogelijk volledig habitatwaardig, of bevat delen } \\
\text { die mogelijk habitatwaardig zijn. Dit betreft percelen die omwille van de vroegere vertaalslag uit } \\
\text { de BWK niet eenduidig vertaald konden worden naar een habitattype. } \\
\text { Deze kennislacus worden opgelost bij herkarteringen. }\end{array}$ \\
\hline
\end{tabular}




\section{Referenties}

Agentschap voor Landbouw en Visserij (2017). Geïntegreerd Controle- en Beheerssysteem. Eenmalige perceelsregistratie. Versie 2016. GIS-bestand. Brussel.

Agentschap voor Landbouw en Visserij (2018). Geïntegreerd Controle- en Beheerssysteem. Eenmalige perceelsregistratie. Versie 2017. GIS-bestand. Brussel.

Bervoets L., Schneiders A. \& Wils C. (1991). Onderzoek naar de verspreiding en de typologie van ecologisch waardevolle waterlopen in Vlaanderen. Deel I. Het Denderbekken. Ministerie van de Vlaamse Gemeenschap, departement Leefmilieu en Infrastructuur (LIN), Administratie Milieu, Natuur en Landinrichting (AMINAL), Dienst Water en Bodem, Brussel. 47 pp. + kaartbijlagen.

Bervoets L., Schneiders A. \& Wils C. (1993). Onderzoek naar de verspreiding en de typologie van ecologisch waardevolle waterlopen in Vlaanderen. Deel V. Demerbekken. Ministerie van de Vlaamse Gemeenschap, departement Leefmilieu en Infrastructuur (LIN), Administratie Milieu, Natuur en Landinrichting (AMINAL), Dienst Water en Bodem, Brussel.

Bervoets L., Schneiders A. \& Wils C. (1996). Onderzoek naar de verspreiding en de typologie van ecologisch waardevolle waterlopen in Vlaanderen. Deel II. Netebekken. Ministerie van de Vlaamse Gemeenschap, departement Leefmilieu en Infrastructuur (LIN), Administratie Milieu-, Natuur-, Land- en Waterbeheer (AMINAL), Afdeling Water, Brussel. 38 pp. + kaartbijlagen.

Bervoets L., Schneiders A. \& Wils C. (1996). Onderzoek naar de verspreiding en de typologie van ecologisch waardevolle waterlopen in Vlaanderen. Deel III. Maasbekken. Ministerie van de Vlaamse Gemeenschap, departement Leefmilieu en Infrastructuur (LIN), Administratie Milieu-, Natuur-, Land- en Waterbeheer (AMINAL), Afdeling Water, Brussel. 40 pp. + kaartbijlagen.

Bervoets L., Schneiders A. \& Wils C. (1996). Onderzoek naar de verspreiding en de typologie van ecologisch waardevolle waterlopen in Vlaanderen. Deel IV. Dijlebekken. Ministerie van de Vlaamse Gemeenschap, departement Leefmilieu en Infrastructuur (LIN), Administratie Milieu-, Natuur-, Land- en Waterbeheer (AMINAL), Afdeling Water, Brussel, 40 pp. + kaartbijlagen.

Bervoets L., Nagels A., Schneiders A. \& Wils C. (1996). Onderzoek naar de verspreiding en de typologie van ecologisch waardevolle waterlopen in Vlaanderen. Deel VI. IJzerbekken. Ministerie van de Vlaamse Gemeenschap, departement Leefmilieu en Infrastructuur (LIN), Administratie Milieu-, Natuur-, Land- en Waterbeheer (AMINAL), Afdeling Water, Brussel. 46 pp. + kaartbijlagen.

Bervoets L., Schneiders A. \& Wils C. (1996). Onderzoek naar de verspreiding en de typologie van ecologisch waardevolle waterlopen in Vlaanderen. Deel VII. Bekken van de Beneden-Zeeschelde. Ministerie van de Vlaamse Gemeenschap, departement Leefmilieu en Infrastructuur (LIN), Administratie Milieu-, Natuur-, Land- en Waterbeheer (AMINAL), Afdeling Water, Brussel. 56 pp. + kaartbijlagen.

Bervoets L., Schneiders A. \& Wils C. (1996). Onderzoek naar de verspreiding en de typologie van ecologisch waardevolle waterlopen in Vlaanderen. Deel VIII. Bekken van de Boven-Schelde. Ministerie van de Vlaamse Gemeenschap, departement Leefmilieu en Infrastructuur (LIN), Administratie Milieu-, Natuur-, Land- en Waterbeheer (AMINAL), Afdeling Water, Brussel.

Bervoets L., Schneiders A. \& Wils C. (1996). Onderzoek naar de verspreiding en de typologie van ecologisch waardevolle waterlopen in Vlaanderen. Deel IX. Bekken van de polders en de Gentse kanalen. Ministerie van de Vlaamse Gemeenschap, departement Leefmilieu en Infrastructuur (LIN), Administratie Milieu-, Natuur-, Land- en Waterbeheer (AMINAL), Afdeling Water, Brussel. 53 pp. + kaartbijlagen.

Bervoets L., Schneiders A. \& Wils C. (1996). Onderzoek naar de verspreiding en de typologie van ecologisch waardevolle waterlopen in Vlaanderen. Deel X. Leiebekken. Ministerie van de Vlaamse Gemeenschap, departement Leefmilieu en Infrastructuur (LIN), Administratie Milieu-, Natuur-, Land- en Waterbeheer (AMINAL), Afdeling Water, Brussel. 41 pp. + kaartbijlagen. 
Bervoets L., Schneiders A. \& Wils C. (1996). Onderzoek naar de verspreiding en de typologie van ecologisch waardevolle waterlopen in Vlaanderen. Deel XI. Zennebekken. Ministerie van de Vlaamse Gemeenschap, departement Leefmilieu en Infrastructuur (LIN), Administratie Milieu-, Natuur-, Land- en Waterbeheer (AMINAL), Afdeling Water, Brussel. 45 pp. + kaartbijlagen.

Cornelis J., Hermy M., Roelandt B., De Keersmaeker L. \& Vandekerkhove K. (2009). Bosplanten-gemeenschappen in Vlaanderen, een typologie gebaseerd op de kruidlaag. INBO.M.2009.5. ANB \& INBO, Brussel.

Decleer K. (red.) (2007). Europees beschermde natuur in Vlaanderen en het Belgisch deel van de Noordzee: habitattypen: dier- en plantensoorten. Mededelingen van het Instituut voor Natuur- en Bosonderzoek, INBO.M.2007.1. Brussel. 584 pp.

De Knijf G., Guelinckx R., T'jollyn F. \& Paelinckx D. (2010). Biologische Waarderingskaart, versie 2. Indicatieve situering van de faunistisch belangrijke gebieden (Rapport en digitaal bestand). Rapporten van het Instituut voor Natuur- en Bosonderzoek 2010 INBO.R.2010.31. Instituut voor Natuur- en Bosonderzoek. Brussel. 20 pp. + GISbestand.

De Saeger S., De Blust G., Oosterlynck P. \& Paelinckx D. (2016a). BWK en Habitatkartering, een praktische handleiding. Deel 2: de heidesleutel. Versie1, maart 2016. Rapporten van het Instituut voor Natuur- en Bosonderzoek 2016 (11613662). Instituut voor Natuur- en Bosonderzoek, Brussel.

De Saeger S., Oosterlynck P., Guelinckx R. \& Paelinckx D. (2016b). BWK en Habitatkartering, een praktische handleiding. Deel 1: methodologie: karteerregels, karteringseenheden en hoofdsleutel. Versie1, maart 2016. Rapporten van het Instituut voor Natuur- en Bosonderzoek 2016 (11613609). Instituut voor Natuur- en Bosonderzoek, Brussel.

De Saeger S. et al. (in voorbereiding). BWK en Habitatkartering, een praktische handleiding. Deel 7: sleutel voor duin en kustkartering. Rapporten van het Instituut voor Natuur- en Bosonderzoek, Brussel.

De Saeger et al. (in voorbereiding). BWK en Habitatkartering, een praktische handleiding. Deel 1: methodologie: karteerregels, karteringseenheden, hoofdsleutel en kleine landschapselementen. Versie2. Instituut voor Natuur- en Bosonderzoek, Brussel.

De Saeger S., Oosterlynck P. \& Paelinckx D. (2017). The Biological Valuation Map (BVM): a field-driven survey of land cover and vegetation in the Flemish Region of Belgium. Documents phytosociologiques - Actes du colloque de SaintMandé 2012 - Prodrome et cartographie des végétations de France - 2017 - Vol. 6: 372-382.

De Saeger S., Guelinckx R., Oosterlynck P., De Bruyn A., Debusschere K., Dhaluin P., Erens R., Hendrickx P., Hendrix R., Hennebel D., Jacobs I., Kumpen M., Opdebeeck J., Ruymen J., Spanhove T., Tamsyn W., Van Oost F., Van Dam G., Van Hove M., Wils C. \& Paelinckx D. (red.) (2018). Biologische Waarderingskaart en Natura 2000 Habitatkaart, uitgave 2018. Rapporten van het Instituut voor Natuur- en Bosonderzoek 2018 (71). Instituut voor Natuur- en Bosonderzoek, Brussel.

De Saeger S. \& Lahaye M. (2019). Rotsachtige habitats en grotten (8310). In: Paelinckx D., De Saeger S., Oosterlynck P., Vanden Borre J., Westra T., Denys L., Leyssen A., Provoost S., Thomaes A., Vandevoorde B. \& Spanhove T. (2019). Regionale staat van instandhouding voor de habitattypen van de Habitatrichtlijn. Rapportageperiode 2013 - 2018. Rapporten van het Instituut voor Natuur- en Bosonderzoek 2019 (13). Instituut voor Natuur- en Bosonderzoek, Brussel. https://doi.org/10.21436/inbor.16122667

De Saeger S., Lommelen E., Lahaye M., Palmans G. \& Vanderhaeghe F. (2020). Habitatquarries: distribution of underground marl quarries closed to the public in the Flemish Region and border areas, with the Flemish distribution of Natura 2000 habitat type 8310 (version habitatquarries_2020v1). [Data set]. Zenodo. http://doi.org/10.5281/zenodo.3784149

De Saeger S., Guelinckx R., Oosterlynck P., Erens R., Hennebel D., Jacobs I., Van Oost F., Van Dam G., Van Hove M., Wils C. \& Paelinckx D. (red.)(2016). Biologische Waarderingskaart en Natura 2000 Habitatkaart, uitgave 2016. Rapporten van het Instituut voor Natuur- en Bosonderzoek 2016 (12049231). Instituut voor Natuur- en Bosonderzoek, Brussel. 
De Saeger S., Guelinckx R. , Van Dam G., Oosterlynck P., Van Hove M., Wils C. \& Paelinckx D. (red.) (2014). Biologische Waarderingskaart en Natura 2000 Habitatkaart, uitgave 2014. Rapporten van het Instituut voor Natuuren Bosonderzoek 2014 (1698392). Instituut voor Natuur- en Bosonderzoek, Brussel. 28 pp. + GIS-bestand

De Saeger S., Ameeuw G., Berten B., Bosch H., Brichau I., De Knijf G., Demolder H., Erens G., Guelinckx R., Oosterlynck P., Rombouts K., Scheldeman K., T'jollyn F., Van Hove M., Van Ormelingen J., Vriens L., Zwaenepoel A., Van Dam G., Verheirstraeten M., Wils C. \& Paelinckx D. (2010). Biologische Waarderingskaart, versie 2.2. Rapporten van het Instituut voor Natuur- en Bosonderzoek 2010 (36). Brussel. 34 pp. + GIS-bestand.

De Saeger S., Louette G., Oosterlynck P., Paelinckx D. \& Hoffmann M. (2013). Historisch Permanent Grasland in de landbouwstreek 'Polders' anno 2013. Technisch rapport campagne 2013. Rapporten van het Instituut voor Natuuren Bosonderzoek 2013 (896909). Instituut voor Natuur- en Bosonderzoek, Brussel. Brussel. 71 pp. + GIS-bestand.

De Saeger S. en Wouters J. (2017). BWK en Habitatkartering, een praktische handleiding. Deel 5: de graslandsleutel. Rapporten van het Instituut voor Natuur- en Bosonderzoek 2018 (4). Instituut voor Natuur- en Bosonderzoek, Brussel.

European Commission (2007). Interpretation manual of European Union habitats. European commission, DG Environment.

Leyssen A., Denys L. \& Smeekens V. (2020). Indicatieve situering van het Natura 2000 habitattype 3260 Submontane en laaglandrivieren met vegetaties behorende tot het Ranunculion fluitantis en het Callitricho-Batrachion. Uitgave 2020 (versie 1.7). Rapporten van het Instituut voor Natuur- en Bosonderzoek 2020 (34). Instituut voor Natuur-en Bosonderzoek, Brussel.

Maris T., S. Baeten, T. Van Den Neucker \& P. Meire (2016). Onderzoek naar de gevolgen van het Sigmaplan, baggeractiviteiten en havenuitbreiding in de Zeeschelde op het milieu. Geïntegreerd eindverslag van het onderzoek verricht in 2016, deelrapport Intergetijdengebieden. ECOBE 016-R207 Universiteit Antwerpen, Antwerpen.

Oosterlynck P. et al. (in voorbereiding). BWK en Habitatkartering, een praktische handleiding. Deel 6: de moerassleutel. Rapporten van het Instituut voor Natuur- en Bosonderzoek, Brussel.

Oosterlynck P. (2020). Distribution of the Natura 2000 habitat type 7220 (Cratoneurion) in Flanders, Belgium (version 2020) (Version habitatsprings_2020v2) [Data set]. Zenodo. http://doi.org/10.5281/zenodo.3784149

Paelinckx D., De Saeger S., Oosterlynck P., Demolder H., Guelinckx R., Leyssen A., Van Hove M., Weyembergh G., Wils C., Vriens L., T'jollyn F., Van Ormelingen J., Bosch H., Van de Maele J., Erens G., Adams Y., De Knijf G., Berten B., Provoost S., Thomaes A., Vandekerkhove K., Denys L., Packet J., Van Dam G. \& Verheirstraeten M. (2009). Habitatkaart, versie 5.2. Indicatieve situering van de Natura 2000 habitats en de regionaal belangrijke biotopen. Integratie en bewerking van de Biologische Waarderingskaart, versie 2. Rapporten van het Instituut voor Natuur- en Bosonder-zoek 2009 (Rapport en GIS-bestand INBO.R.2009.4). Instituut voor Natuur- en Bosonderzoek, Brussel.

Paelinckx D., De Saeger S., Oosterlynck P., Vanden Borre J., Westra T., Denys L., Leyssen A., Provoost S., Thomaes A., Vandevoorde B. en Spanhove T. (2019). Regionale staat van instandhouding voor de habitattypen van de Habitatrichtlijn. Rapportageperiode 2013 - 2018. Rapporten van het Instituut voor Natuur- en Bosonderzoek 2019 (13). Instituut voor Natuur- en Bosonderzoek, Brussel. http://doi.org/10.21436/inbor.16122667

Roelandt B. (2012). Een vegetatieanalyse van het Zoniënwoud. Agentschap Natuur en Bos, Brussel.

Scheers K., Packet J., Denys L., Smeekens V. \& De Saeger S. (2016). BWK en Habitatkartering, een praktische handleiding. Deel 3: handleiding voor het typeren van de stilstaande wateren in Vlaanderen. Rapporten van het Instituut voor Natuur- en Bosonderzoek 2016 (11613720). Instituut voor Natuur- en Bosonderzoek, Brussel.

Vandekerkhove K., De Saeger S., Thomaes A., De Keersmaeker L., Oosterlynck P., Van Oost F. \& Jacobs I. (2016). BWK en Habitatkartering, een praktische handleiding. Deel 2: de bossleutel. Versie1, maart 2016.. Rapporten van het Instituut voor Natuur- en Bosonderzoek 2016 (11613777). Instituut voor Natuur- en Bosonderzoek, Brussel.

Vandevoorde B. et al. (In voorbereiding). Vegetatiekaart IJzermonding. Instituut voor Natuur- en Bosonderzoek, Brussel. 
Vandevoorde B. \& Van Lierop F. (2018). Vegetatiekaart. In: Van Ryckegem G., Van Braeckel A., Elsen R., Speybroeck J., Vandevoorde B., Mertens W., Breine J., Spanoghe G., Bezdenjesnji O., Buerms D., De Beukelaer J., De Regge N., Hessel K., Lefranc C., Soors J., Terrie T., Van Lierop F. \& Van den Bergh E. (2018). MONEOS - Geïntegreerd datarapport INBO: Toestand Zeeschelde 2017: monitoringsoverzicht en $1^{\text {ste }}$ lijnsrapportage Geomorfologie, diversiteit Habitats en diversiteit Soorten. Rapporten van het Instituut voor Natuur- en Bosonderzoek 2018 (74). Instituut voor Natuur- en Bosonderzoek, Brussel. DOI: doi.org/10.21436/inbor.15000892

Vriens L., Bosch H., De Knijf G., De Saeger S., Oosterlynck P., Guelinckx R., T'jollyn F., Van Hove M. \& Paelinckx D. (2011). De Biologische Waarderingskaart. Biotopen en hun verspreiding in Vlaanderen en het Brussels Hoofdstedelijk Gewest. Mededelingen van het Instituut voor Natuur- en Bosonderzoek, INBO.M.2011.1. Brussel. $416 \mathrm{pp}$.

Weblink 1: https://www.ecopedia.be/pagina/de-biologische-waarderingskaart-0

Weblink 2: https://www.inbo.be/nl/naar-een-natuurtypologie-voor-vlaanderen

Weblink 3: www.inbo.be/nl/handleiding-en-veldsleutels 


\section{Rapporten Biologische Waarderingskaart}

Ameeuw G., Berten R. \& Paelinckx D. (2006). Biologische Waarderingskaart, versie 2: Toelichting bij de kaartbladen 33-41. Rapport en digitaal bestand INBO.R.2006.35. Instituut voor Natuur- en Bosonderzoek, Brussel.

Berten B., Erens G., Ameeuw G., T'jollyn F. \& Paelinckx D. (2010). Biologische Waarderingskaart, versie 2. Toelichting bij de kaartbladen 26 (Rapport en digitaal bestand). Rapporten van het Instituut voor Natuur- en Bosonderzoek (2010 INBO.R.2010.7). Instituut voor Natuur-en Bosonderzoek, Brussel.

Bosch H., Van Hove M., De Saeger S. \& Paelinckx D. (2006). Biologische Waarderingskaart, versie 2. Kaartbladen 1-7. Rapport en digitaal bestand INBO.R.2007.7. Instituut voor Natuur- en Bosonderzoek, Brussel.

Bosch H., Vriens L., De Saeger S., Guelinckx R., Oosterlynck P., T'jollyn F., Scheldeman K., Heirman J., Van Hove M. \& Paelinckx D. (2010). Biologische Waarderingskaart, versie 2. Toelichting bij de kaartbladen 24 (Rapport en digitaal bestand). Rapporten van het Instituut voor Natuur- en Bosonderzoek 2010 (INBO.R.2010.2). Instituut voor Natuuren Bosonderzoek, Brussel.

De Knijf G., Vriens L. \& Paelinckx D. (2004). Biologische Waarderingskaart, versie 2. Kaartbladen 29-37. Rapport en digitaal bestand. Instituut voor Natuurbehoud IN.R2004.05. Brussel.

De Knijf G., Adams Y. \& Paelinckx D. (2010). Biologische Waarderingskaart, versie 2. Toelichting bij de kaartbladen 30-38 (Rapport en digitaal bestand). Rapporten van het Instituut voor Natuur- en Bosonderzoek 2010 (INBO.R.2010.6). Instituut voor Natuur- en bosonderzoek, Brussel.

De Saeger S., Demolder H. \& Paelinckx D. (2006). Biologische Waarderingskaart, versie 2. Kaartbladen 6-14. Rapport en digitaal bestand. INBO.R.2007.8. Instituut voor Natuur- en Bosonderzoek, Brussel.

De Saeger S., Vriens L. \& Paelinckx D. (2006). Biologische Waarderingskaart, versie 2. Kaartbladen 22. Rapport en digitaal bestand. Instituut voor Natuur- en Bosonderzoek INBO.R2006.04. Brussel.

De Saeger S., Bosch H., Van Hove M., Vriens L. \& Paelinckx D. (2009). Biologische Waarderingskaart, versie 2. Toelichting bij de kaartbladen 2-8. (Rapport en digitaal bestand). Rapporten van het Instituut voor Natuur- en Bosonderzoek 2009 (INBO.R.2009.35). Instituut voor Natuur- en Bosonderzoek, Brussel.

Erens G., Guelinckx R., Oosterlynck P., Van Ormelingen J., De Knijf G. \& Paelinckx D. (2010). Biologische Waarderingskaart, versie 2. Toelichting bij de kaartbladen 34-35-42. Rapporten van het Instituut voor Natuur- en Bosonderzoek 2010 (Rapport en digitaal bestand INBO.R.2010.17). Instituut voor Natuur- en bosonderzoek, Brussel.

Guelinckx R., Oosterlynck P. \& Paelinckx D. (2004). Biologische Waarderingskaart, versie 2. Kaartbladen 32. Rapport en digitaal bestand, Instituut voor Natuurbehoud IN.R2004.06. Brussel.

Oosterlynck P., Guelinckx R., Van Ormelingen J., Erens G., Berten B., De Saeger S. \& Paelinckx D. (2010). Biologische Waarderingskaart, versie 2. Toelichting bij de kaartbladen 25. Rapporten van het Instituut voor Natuur- en Bosonderzoek 2010 (Rapport en digitaal bestand INBO.R.2010.16). Instituut voor Natuur- en Bosonderzoek, Brussel.

Scheldeman K., Lust P., Vriens L., Durwael L., T'jollyn F., Bosch H. \& Paelinckx D. (2009). Biologische Waarderingskaart, versie 2. Kaartbladen 5-13 (Rapport en digitaal bestand). Rapporten van het Instituut voor Natuur- en Bosonderzoek 2009 (INBO.R.2009.44). Instituut voor Natuur- en Bosonderzoek, Brussel.

T'jollyn F., Vandenbussche V., Scheldeman K. \& Paelinckx D. (2006). Biologische Waarderingskaart, versie 2. Kaartbladen 4-11-12. Rapport en digitaal bestand INBO.R.2007.6. Instituut voor Natuur- en Bosonderzoek, Brussel.

Vriens L., Van Hove M., Paelinckx D., Heirman J., Vanallemeersch R. \& Zwaenepoel A. (2004). Biologische Waarderingskaart, versie 2. Kaartbladen 15. Rapport en digitaal bestand IN. R2004.04. Instituut voor Natuurbehoud, Brussel.

Vriens L., T'jollyn F., Lust P., Scheldeman K., De Knijf G. \& Paelinckx D. (2009). Biologische Waarderingskaart, versie 2. Kaartbladen 21 (Rapport en digitaal bestand). Rapporten van het Instituut voor Natuur-en Bosonderzoek 2009 (INBO.R.2009.43). Instituut voor Natuur- en Bosonderzoek, Brussel. 